EMBRYARIDDLE
Aeronautical University

SCHOLARLY COMMONS

\section{International Journal of Aviation,} Aeronautics, and Aerospace

\title{
Simulations on Optimization of Liquid Spray Burners \& Operating Parameters
}

\author{
Pallavi Gajjar \\ SRM Institute of Science and Technology, Kattankulathur, pallaviuniversity@gmail.com \\ Vinayak Malhotra \\ SRM Institute of Science \& Technology, Kattankulathur, vinn99@gmail.com
}

Follow this and additional works at: https://commons.erau.edu/ijaaa

Part of the Heat Transfer, Combustion Commons, and the Propulsion and Power Commons

\section{Scholarly Commons Citation}

Gajjar, P., \& Malhotra, V. (2019). Simulations on Optimization of Liquid Spray Burners \& Operating Parameters. International Journal of Aviation, Aeronautics, and Aerospace, 6(3). https://doi.org/ 10.15394/ijaaa.2019.1346

This Article is brought to you for free and open access by the Journals at Scholarly Commons. It has been accepted for inclusion in International Journal of Aviation, Aeronautics, and Aerospace by an authorized administrator of Scholarly Commons. For more information, please contact commons@erau.edu. 


\section{Introduction}

Nearly $80 \%$ of the world's energy needs are met by combustion of fossil fuels and petroleum provides approximately $40 \%$ of those needs by mostly fueling automotive and aerospace vehicles. Contrary to providing energy and advancing our civilization, combustion is also ironically the major cause for its downfall due to the adverse effects it has on both the environment and human health. This is because $100 \%$ efficient burning of hydrocarbons hasn't been achieved and practically implemented owing to the multitude of challenges faced during the combustion process. The predominant setback to achieving efficient combustion comes from the presence and propagation of instabilities which are manifested in the reacting flow due to factors inherent and/or external to the flow affecting the smooth functioning of engines. Combustion instability studies can thus go a long way in reducing the global NOx and $\mathrm{CO} 2$ emissions alongside increasing the efficiency and stability of systems.

Since a majority of instabilities tend to arise from the point of fuel injection itself in a combustor, an optimal characterization of spray burner performance is mandatory for the effective working of the engine in use. Spray burners form an essential part of any liquid propulsion system as they are responsible for injecting, atomizing, mixing and combusting the liquid fuel. Spray combustion used in aerospace applications like the liquid rocket engines, gas turbines or any other controlled environment for that matter places a huge emphasis on safe and effective operations. These applications make use of relatively small amounts of propellant volumes to generate enormous amounts of energy through combustion for producing thrust. Thus, the role of spray burners in combustion stability is an aspect yet to be comprehensively analyzed owing to the heterogeneous heat and mass transfer and so the present work focuses on the combustion characteristics of spray burners and is motivated by the need to have stable and efficient engine performance.

Liquid fuels are used in the majority of the combustion systems owing to the fact that they tend to have higher energy density than the gaseous fuels. They are also relatively cleaner and do not leave behind ash or minerals like solid fuels. However, liquid fuels need to be vaporized or atomized into droplets before they can be injected into the combustion chamber (Raghavan, 2016).

Spray burners promote efficient combustion of liquid fuel. Based on the mechanisms employed to vaporize liquid fuels and to mix the fuel vapor with the oxidizer, the liquid spray burners can be largely categorized as (a) Wick burners, (b) Pre-vaporizing burners, (c) Vaporizing burners, (d) Porous burners, and (e) Atomizing burners. All of the mentioned burners except the atomizing burner are 
mainly used with moderately or highly volatile liquid fuels and can't be employed for steady burning of different grades of fuels which can be multi-component in nature displaying non-uniform evaporation properties. To speed up the combustion process, vaporization is accelerated by the mechanical means of a nozzle in atomizing burners.

Atomization of fuels is done to disintegrate the liquid into tiny droplets which can evaporate and burn at the specified rate in the combustion chamber. Methods of atomization are categorized based on the fuel flow rate and velocity of the surrounding gas as (a) Pressure atomization, (b) Rotary atomization, and (c) Twin-fluid atomization. In case of pressure atomization and rotary atomization, a stream of fuel emerges with high velocity into the quiescent surroundings while, in case of twin-fluid atomization, a slow stream of fuel comes in contact with a high-velocity stream of gas.

In pressure atomizers, the fuel emerges out with a high velocity and disintegrates into droplets. There are 6 main types of pressure atomizers viz. (a) Plain orifice, (b) Simplex, (c), Duplex (d), Dual orifice (e), Spill return, and (f) Fan spray. As this study aims to optimize the spray burner in context of combustion applications for the aerospace domain, a Simplex type pressure atomizer (also called the pressure-swirl atomizer) is opted. The main advantages it offers in comparison to other types of atomizers are that it has a wide spray angle, is simple in design and has low power requirements (Raghavan, 2016).

The use of liquid fuel spray combustion commenced over the past century when it was discovered that the atomization of fuels provided a convenient means of obtaining self-sustaining flames. The fuel spray emanating from the nozzle evaporates and burns with the surrounding oxidizer to produce a diffusion flame. The way the fuel vapor mixes with the oxidant determines how the overall combustion proceeds. In real systems, a wide range of droplet sizes and fuel components are involved and both homogenous and heterogeneous modes of combustion can occur simultaneously (Locklin \& Barrett, 1975; Panchagnula, 1999; Williams, 1990).

There are numerous parameters that affect the nozzle performance and in turn spray combustion but the 3 main parameters taken into scrutiny for the present work were:

- Spray Angle $\left(^{\circ}\right)$

- Volume flow rate (LPM)

- Droplet velocity $(\mathrm{m} / \mathrm{s})$ 
The spray angle $(\theta)$ is governed by the design of the swirl chamber and the orifice. It is expressed for cold flow in Equation 1 as a function of the discharge coefficient $\left(C_{d}\right)$, the angle at which at which the fuel is brought into the swirl chamber $(\beta)$, the radius of the fuel injection slots in the swirl chamber $\left(r_{i}\right)$, the radius of the swirl chamber $\left(r_{s}\right)$, the ratio of the cross-sectional area of the air core $\left(A_{o a}\right)$ to the cross-sectional area of the exit orifice $\left(A_{o}\right)$ i.e. $x=\frac{A_{o a}}{A_{o}}$ and $K$.

$$
\sin \theta=\frac{\pi}{2} \frac{C_{d} \sin \beta}{K(1+x)}\left(\frac{r_{i}}{r_{s}}\right)
$$

Where, $K$ is given by:

$$
K=\sqrt{\left(\frac{\pi^{2}}{32}\right) \frac{(1-x)^{3}}{x^{2}}\left(\frac{r_{i}}{r_{s}}\right)^{2} \sin ^{2} \beta}
$$

An explicit relationship between spray angle and the primary combustion characteristics is yet to be established but from prior studies, it has been observed that high spray angles increase combustion efficiency alongside increasing the combustor wall temperature as well (Datta \& Som, 1999). Viscosity too has an effect on the effective spray angle. If the viscosity is high enough, the effective spray angle may collapse to the extent that a long, very narrow flame results. On decreasing the effective spray angle, the droplet size also increases and it might increase to the point that it may be impossible to maintain a steady flame front and the fuel would burn off the back wall of the combustion chamber. With intermittent ignition, the flame might leave the burner completely and with constant ignition may be long, narrow and noisy.

Nozzles for spray burners are mainly provided in two types of spray patterns viz. solid cone and hollow cone. For volume flow rates above $3.00 \mathrm{GPH}$ ( 0.19 LPM) as used in this study, it is advisable to standardize on solid cone sprays for smoother ignition. From prior experiments, if combustion efficiency is the only criterion emphasized on in conventional burners, a $45^{\circ}$ or $60^{\circ}$ solid cone nozzle is preferred. However, many of these units when fired into round or square combustion chambers under certain conditions have been found to pulsate or rumble (Olson, n.d., p. 9).

For most pressure nozzles the liquid flow rate is proportional to the square root of the injection pressure differential. This is also true for the WL $1 / 2$ simplex pressure nozzle used for this study shown in Figure 1.

High values of droplet (or particle) velocity tend to increase the flame penetration length which is essential for several industrial applications. Droplet 
velocity of the fuel also plays a quintessential role in determining the magnitude of instabilities in the combustion system. It has been instrumental in this study to validate the simulation results analytically.

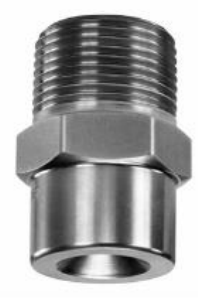

(a)
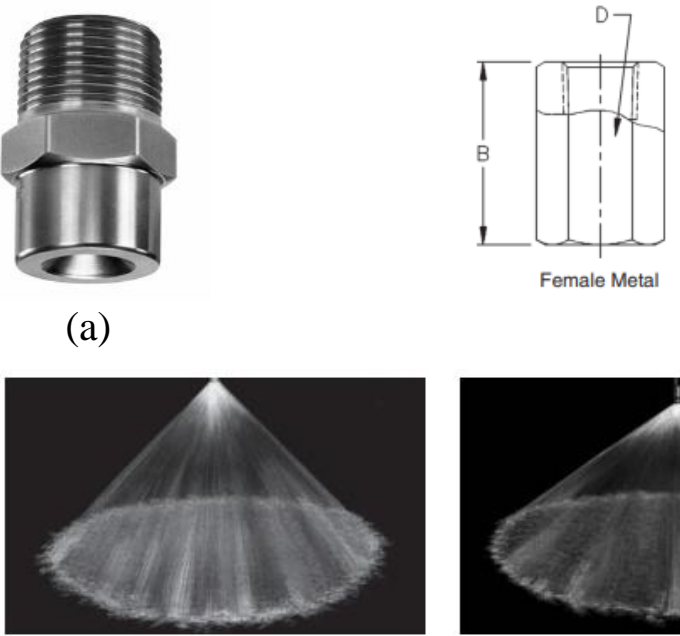

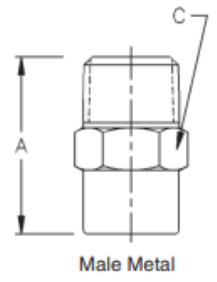

(b)

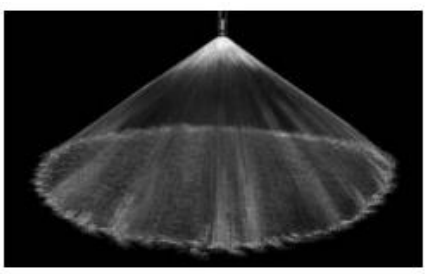

(c)

Figure 1. Picture courtesy of CBETE Inc. (a) WL $1 / 2$ nozzle taken for this study (b) Schematic of male and female parts of WL $1 / 2$ nozzle (c) Depiction of $90^{\circ}$ and $120^{\circ}$ full cone spray angles. 


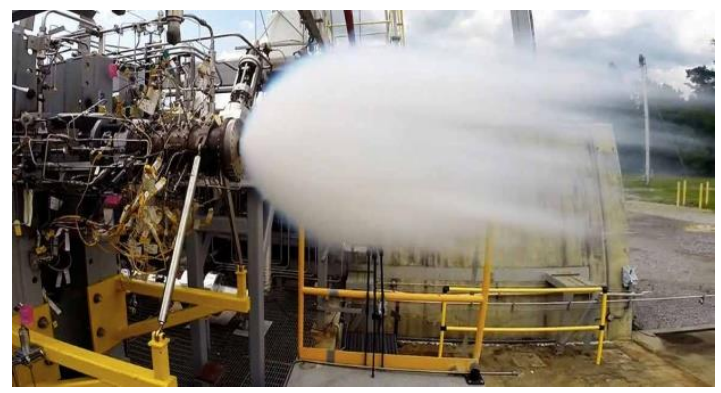

(a)

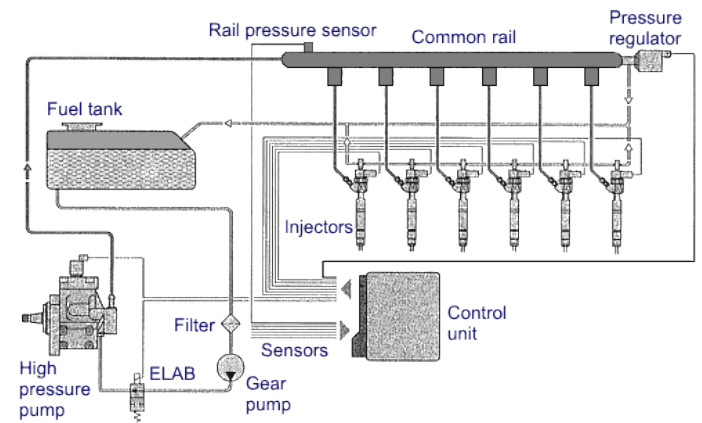

(c)

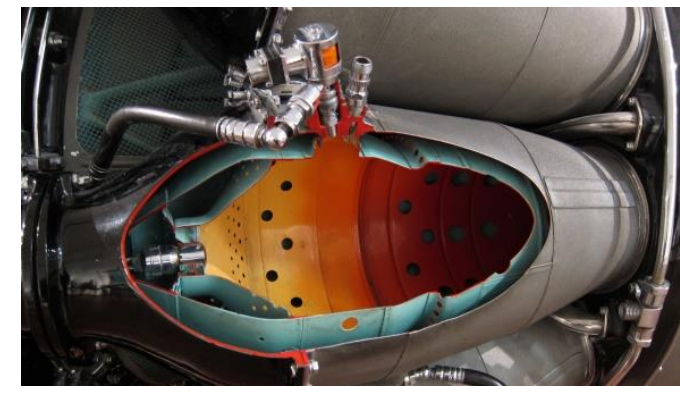

(b)

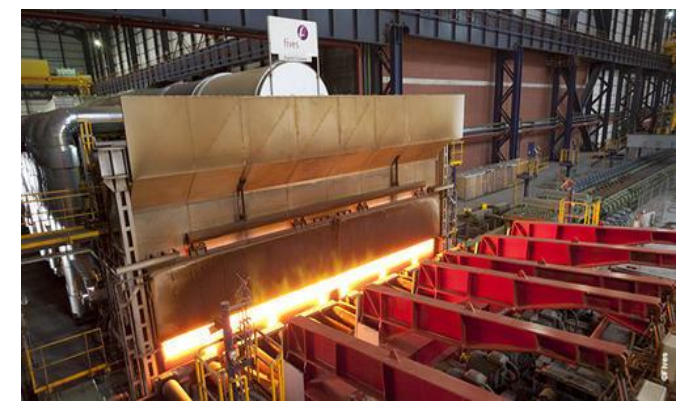

(d)

Figure 2. Applications of spray burners (a) Rocket engine preburner (Picture courtesy of (CAerojet Rocketdyne) (b) Gas turbine engine combustor (Picture courtesy of (CRolls Royce) (c) CI diesel engine (Picture courtesy of @Ecopoint Inc.) (d) Metal reheating furnace.

Combustion instabilities are one of the largest risks associated with the development of modern propulsion and energy systems. They have long been a subject of ardent interest and in literature pertaining to high-performance propulsion systems, they are mainly described to be manifested as large amplitude pressure oscillations coupled with heat release and oscillations in the combustor through-flows which can seriously hamper or degrade the engine performance and lead to system failure (due to structural damages) in extreme cases (Mcmanus, Poinsot \& Candel, 1993). Research on combustion instabilities mainly started during the 1950s and 1960s by Summerfield (1951) and Crocco (1965). Early works on this topic were mainly focused on the mechanisms of unstable combustion in solid and liquid propellant rocket motors.

Combustion instability has been seen to develop spontaneously within the system or be initiated by any natural or artificial perturbation external to it. The pressure amplitude of oscillations is said to grow with time only if the energy gain from combustion to the oscillation field is greater than the energy lost. In literature, whether or not a pressure perturbation leads to instability depends on the excitation mechanism and the nature of the driving and damping processes. 
Heat release from chemical reactions is observed to be the major energy source driving unsteady flow oscillations in combustion systems and the energy needed to drive unsteady motions is only an exceedingly small fraction of the heat release from combustion (Culick \& Yang, 1995; Pandalai \& Mongia, 1998).

Mechanisms governing the instabilities are fundamentally complex because they involve interaction between several different physical phenomena viz. unsteady flame propagation leading to unsteady flow velocities, acoustic wave propagation, and natural or forced hydrodynamic instabilities. The intrinsic instabilities result from chemical and thermo-diffusive effects which modify the basic flame propagation rate. The controlling mechanisms vary depending on whether liquid, gaseous or solid propellants are used (Sivashinsky, 1983; Clavin, 1985). The Kelvin-Helmholtz and the Rayleigh-Taylor instabilities are the key mechanisms of hydrodynamic instability. Prior research has shown the importance of hydrodynamic instabilities leading to organized turbulent motion in both reacting and non-reacting flows. In reacting flows, the turbulent structures tend to lead to heat release rate fluctuations which provide the driving component for combustion instability. (Brown, Dunlap, Young, \& Waugh, 1981; Flandro, 1986; Humphrey \& Culick, 1987; Poinsot, Trouve, Veynante, Candel \& Esposito, 1987). The key problem lies in understanding how the flame responds to the flow perturbations as the flame response is dominated by the large-scale structures that arise from underlying instability of flow.

For a fluid mechanic system to be called stable, it has to be stable to all sorts of perturbations. There are numerous values of wavelength $(\lambda)$ that can be imposed on the interface between the two fluids but there is one particular value of wavelength that outperforms all other values in the rate at which it grows. To get an idea of the range in which this value of $\lambda$ lies, linear instability analysis was carried out analytically in 2D x-y coordinate plane. The analysis started by taking the governing equations into consideration viz. the Euler's equations and the Continuity Equation. Mean velocities and pressure fields were established for the unperturbed flow and it was ensured that they were solutions to the governing equations. An infinitesimal perturbation of the order $(\Delta \varepsilon)$ was introduced to the flow and interface variables. The perturbed flow fields were substituted into the governing equations and only linear terms of the order of $(\Delta \varepsilon)$ were retained while the rest were neglected. A sinusoidal perturbation was introduced at the fluid interface which is described by Equation 3 as follows:

$$
y=\eta_{o} e^{(\omega t+i k x)}
$$

Where, $k=\frac{2 \pi}{\lambda}$ is the wave number, $\eta_{o}$ is the initial amplitude of perturbation ( $\sim$ the order of $\Delta \varepsilon$ ) and $e^{\omega t}$ captures the behavior of the wave. $\omega$ could be a complex number given by $\left(\omega=\omega_{r}+i \omega_{i}\right)$. If the real part of $\omega$ i.e. $\omega_{r}$ is 
positive, $e^{\omega t}$ grows with time $t$ and if $\omega_{r}$ is negative, $e^{\omega t}$ decreases with time. Next the kinematic and dynamic boundary conditions were supplied and the normal mode assumption was made which implies that if an initial sinusoidal perturbation is imposed on the interface, then as long as the equations are all linear, the spatial variation in the x-direction would be of the same sinusoidal form as the perturbation wave. In accordance with the assumption, the flow variables were expanded in the form of Eigen functions in space $\left(e^{i k x}\right)$ and time $\left(e^{\omega t}\right)$. The Eigen functions were then substituted in the governing equations and boundary conditions and solved to obtain a set of ordinary differential equations which yielded the complex quadratic Dispersion equation (Equation 4) of the form $\omega=f(k)$.

$$
\left(\rho_{1}+\rho_{2}\right) \omega^{2}+2 i k\left(\rho_{1} U_{1}+\rho_{2} U_{2}\right) \omega-k^{2}\left(\rho_{1} U_{1}^{2}+\rho_{2} U_{2}^{2}\right)+\sigma k^{3}=0
$$

If the real root of $\omega>0$, we get,

$$
\begin{gathered}
k<\frac{\rho_{1} \rho_{2}\left(U_{1}-U_{2}\right)^{2}}{\sigma\left(\rho_{1}+\rho_{2}\right)} \text { or } k_{c}=\frac{\rho_{1} \rho_{2}\left(U_{1}-U_{2}\right)^{2}}{\sigma\left(\rho_{1}+\rho_{2}\right)} \\
\Rightarrow \lambda_{c}=\frac{2 \pi}{k_{c}}
\end{gathered}
$$

Here, $k_{c}$ is the cutoff wavenumber, $\lambda_{c}$ is the cutoff wavelength and $\lambda^{*}$ is the wavelength associated with $k^{*}$. The Dispersion equation gives us the neutral stability bound or the range of $\mathrm{k}$ values and the predominant source of instability (from the $k^{*}$ value) from just 5 parameters viz. densities of the two fluids $\left(\rho_{1}, \rho_{2}\right)$, flow velocities of the two fluids $\left(U_{1}, U_{2}\right)$ and the surface tension $\sigma$. This correspondingly gives us a range of perturbation wavelengths which can manifest themselves as instabilities and also the value of the dominant wavelength $\left(\lambda^{*}\right)$ which would have the maximum growth rate of all wavelengths (Lefebvre, 1989; Bayvel \& Orzechowski, 1993; Panchagnula, 2014).

Combustion instabilities in literature are mostly classified by the oscillation frequencies and grouped into the following categories: low-frequency, intermediate frequency, and high-frequency instabilities (Fernandes \& Heitor, 1996; Krebs et al., 2005; Mongia, Held, Hsiao, \& Pandalai, 2005; Sewell \& Sobieski, 2005), but there is no universally accepted criterion with well-defined frequency boundaries currently available to define these three types of instabilities. Also, prior research has mainly described combustion instabilities from the perspective of pressure oscillations but very little attempt has been made to define instabilities from the perspective of energy losses. This study hence evaluates combustion instability from the energy loss perspective which gives us a better idea about the efficiency of the engine in use. The general form of the Energy Equation (Equation 7) is given by:

$$
\text { Energy }_{\text {net }}=\text { Energy }_{\text {generated }}-\text { Energy }_{\text {lost }}
$$




\section{Motivation and Specific Objectives of the Work}

- To understand the role of droplet velocity, spray angle, volume flow rate and orientation/arrangement of burners as controlling parameters in the operation of liquid spray burners.

- To analyze the combustion efficiency in terms of Generated Heat Release Rate (GHRR) and heat losses (viz. conduction, convection and radiation).

- To understand the effect of combustion instabilities (predominantly intrinsic and hydrodynamic) on spray combustion.

- To suggest ways to control and/or mitigate combustion instabilities in order to make combustion systems energy efficient.

- To redefine combustion instability from the energy perspective by categorizing it based on heat losses experienced by the system.

\section{Simulations and Solution Methodology}

The study utilized the Fire Dynamics Simulator (FDS) and Smokeview (SMV) software developed by NIST. FDS is a CFD software for fire-driven fluid flow which utilizes a direct pressure solver. By default, turbulence is treated using the LES model based on the Navier-Stokes equations appropriate for low-speed ( $<0.3$ Mach), thermally driven flow. The core algorithm uses a second-order accurate FDM approximation (due to rectilinear meshing) and solutions are updated using an explicit second-order Runge-Kutta scheme. FDS uses the mixture-fraction model to calculate lumped species of combustion. Thermal radiation is computed using the FVM technique on the same grid as the flow solver from the radiation transport equation for a gray gas. Lagrangian particles are used to simulate smoke movement and fuel sprays. SMV is a companion visualization program used to display the output of FDS simulations in the form of images and animation (McGrattan, McDermott, Hostikka, \& Floyd, 2010).

The base code comprised of two nozzles facing downwards towards a steel pan placed on a gypsum base as shown in Figure 3. The computational domain was defined with appropriate mesh and its outer solid boundary was maintained at ambient temperature. The gypsum surface and steel pan were defined by allotting their thickness, thermal conductivity, specific heat and density values. Subsequently, composition of the fuel molecule and non-ideal product yields were defined. Heptane is the preferred fuel for the study as it marks 
the 0 point on the octane rating scale and knocks easily. High frequency pressure oscillations have been observed during combustion of Heptane. Since the default mixture fraction combustion model assumes that fuel and oxygen burn when mixed (assuming that the oxygen concentration is above an empirically determined threshold), there was no need to specify an ignition source. The program was coded to linearly increment the heat release from 0 to 10 seconds. Heat release at the end of 10 seconds for the base case was decided as $1 \mathrm{MW}$; based on which, fuel flow rate of 1.96 LPM was taken. Heat released at 10 seconds for the two nozzles was thus calculated as:

$2 \times 1.96 \frac{\mathrm{L}}{\min } \times \frac{10}{60} \frac{\mathrm{min}}{\mathrm{s}} \times 688 \frac{\mathrm{kg}}{\mathrm{m}^{3}} \times \frac{1}{1000} \frac{\mathrm{m}^{3}}{\mathrm{~L}} \times 44500 \frac{\mathrm{kJ}}{\mathrm{kg}}=1000.123 \approx 1 \mathrm{MW}$

The spray angle $\theta$ considered for the base case was $45^{\circ}$ which gave a full spray cone angle of $90^{\circ}$. Droplet velocity and flow rate were taken to be $21 \mathrm{~m} / \mathrm{s}$ and 1.96 LPM ( 2 LPM). Nozzle orientations were varied in the 3D coordinate system as and when needed for a particular case study. The simulation time for all cases was taken to be 10 seconds. Data for wall temperature, flame temperature vectors, heat release rate per unit volume (HRRPUV) and mixture fraction was saved. Additional specifications of the code are given in Table 1. 
Table 1

Major Specifications of the Study

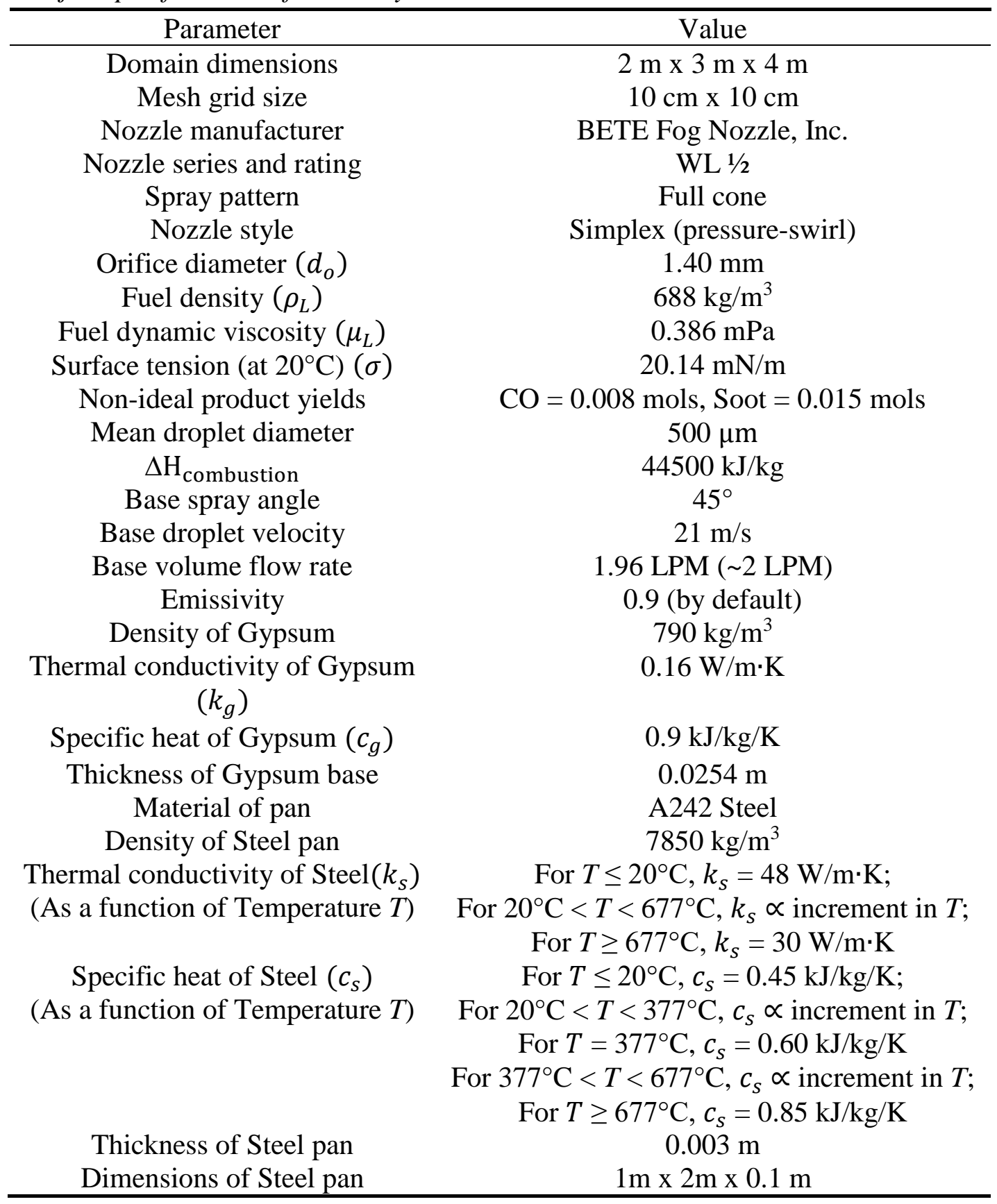




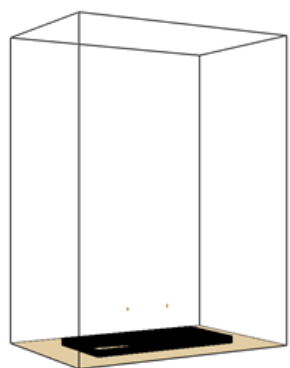

(a)

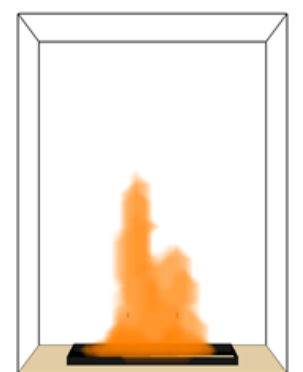

(b)

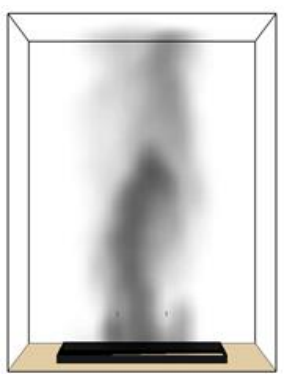

(c)

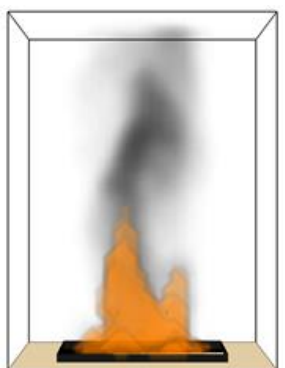

(d)

Figure 3. Depiction of computational domain (a) without fire and soot (b) with fire (c) with soot (d) with both fire and soot.

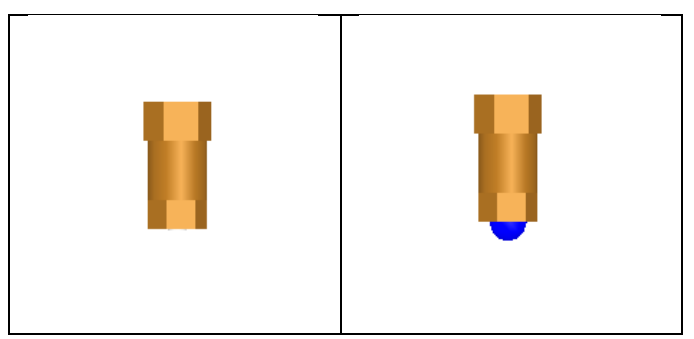

(a)

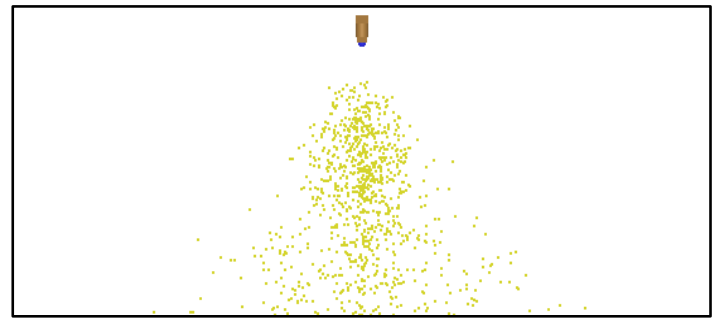

(b)

Figure 4. (a) Depiction of inactive (left) and active (right) nozzles facing downwards (b) Depiction of $45^{\circ}$ spray angle (or $90^{\circ}$ full cone angle).

\section{Results}

\section{Computational Validation of Software Predictions}

Figure 5 represents the plot of GHRR for the base case comprising of two nozzles with their default orientation in the downward direction (facing the steel pan) in the computational domain. Nozzles were placed $0.5 \mathrm{~m}$ away from the steel pan in the z-direction. For this base case, the spray angle $\theta$ was taken to be $45^{\circ}$, fuel flow rate to be 1.96 LPM ( 2 LPM) and droplet velocity to be $21 \mathrm{~m} / \mathrm{s}$. Highest GHRR value recorded for this case was $963 \mathrm{~kW}$ which occurred at 9.67 seconds.

To validate that the presence of nozzles had no role to play in the combustion process, the above base case was taken but the orientation of the 2 nozzles was reversed so that they faced upwards. The GHRR trend of this case 
was compared with another case which had an additional non-active nozzle present in its domain. No deviation in GHRR was found for both cases and so it can be safely stated that the presence of nozzles had no role to play in the combustion process taking place in the domain. Figure 6 depicts the validation result.

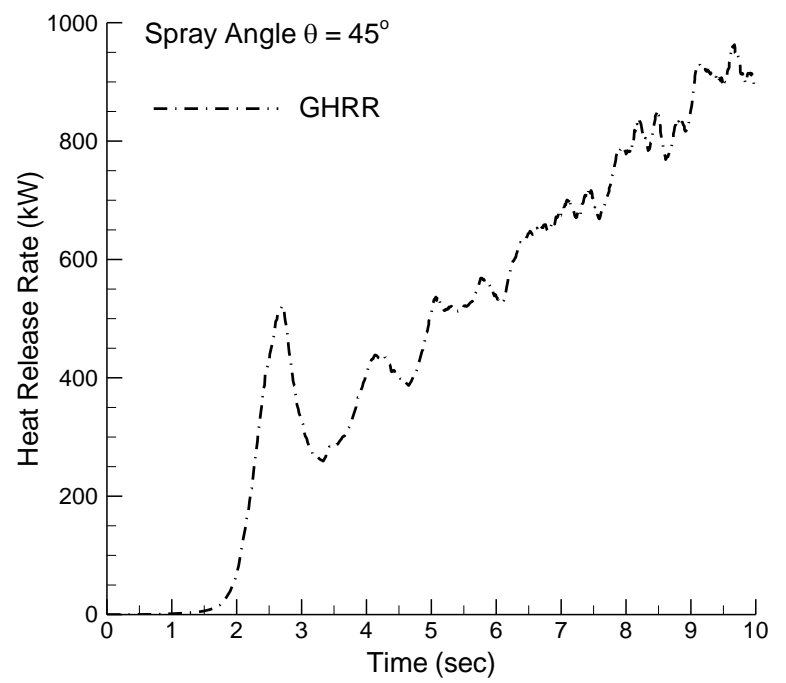

Figure 5. Depiction of GHRR for spray angle $45^{\circ}$, droplet velocity $21 \mathrm{~m} / \mathrm{s}$ and flow rate 2 LPM taken as the base case.

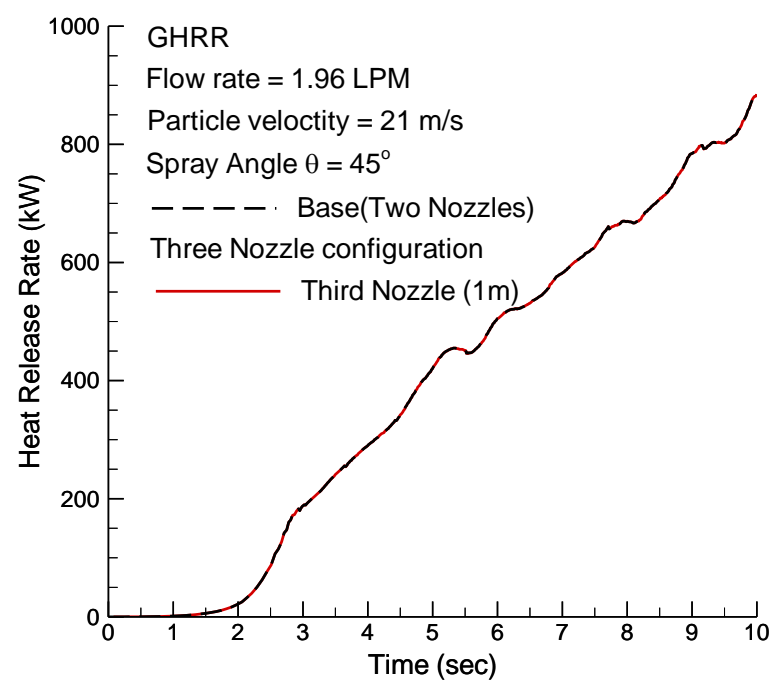

Figure 6. Validation with a third nozzle (non-active) inserted in the base case. 


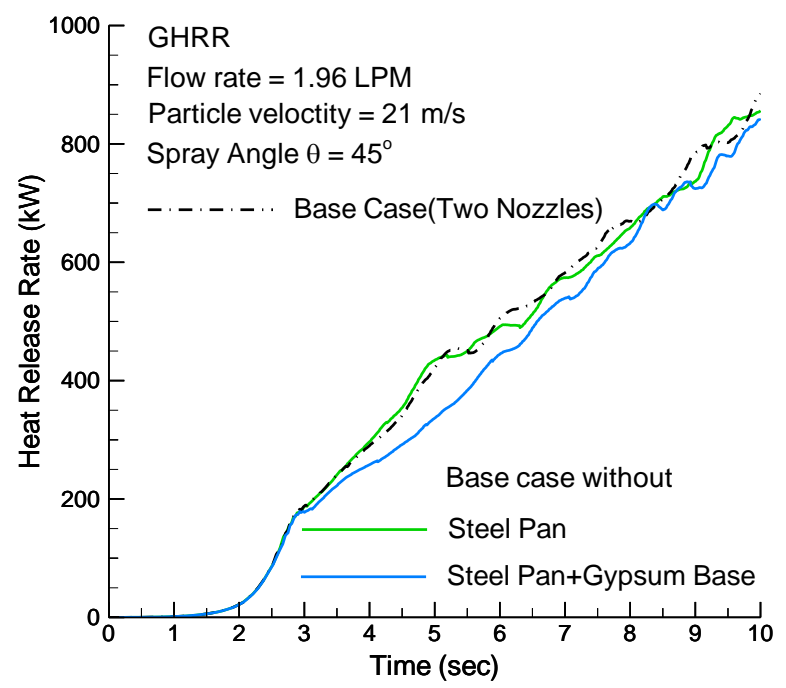

Figure 7. Validation with role of integral components in heat transfer.

To check the role of integral components (present in the domain) in heat transfer, three cases were taken (a) base case consisting of both the steel pan and gypsum base (b) base case without the steel pan and (c) base case without steel pan and gypsum base. From Figure 7 we can tell that the heat release rate varies for the 3 cases as expected. Hence the software is sensitive towards different materials and takes them into account while performing the calculations.

\section{Further Computational Validation of Software Predictions and the Effect of Droplet Velocity Variation on Spray Burner Heat Transfer}

Next, the effect of droplet (or particle) velocity was seen on spray burner performance. The original base case with the two nozzles facing downwards was taken and keeping the rest of the parameters untouched; only the droplet velocities were systematically varied and results were plotted.

Non-premixed flames are characterized by large density differences which lead to development of instabilities that are global in nature. These instabilities affect the entire flow field with a distinct frequency that scales with the macroscopic properties of the flow. The trend of GHRR in Figure 8 for droplet velocity $1 \mathrm{~m} / \mathrm{s}$ is a peculiar example of the amplified heat release response to the oscillating flow perturbations due to the instabilities present in the spray. The order of heat release fluctuations resonates with the order of perturbations caused 
due to instabilities present in the flow field. This was quantitatively seen by calculating the order of flow perturbation wavelengths for droplet velocities 1 $\mathrm{m} / \mathrm{s}, 21 \mathrm{~m} / \mathrm{s}, 25 \mathrm{~m} / \mathrm{s}$ and $50 \mathrm{~m} / \mathrm{s}$ for comparison.

For $U_{1}=1 \mathrm{~m} / \mathrm{s}, U_{2}=0 \mathrm{~m} / \mathrm{s}, \rho_{1}=688 \mathrm{~kg} / \mathrm{m}^{3}, \rho_{2}=1.429 \mathrm{~kg} / \mathrm{m}^{3}, \sigma=0.002014$ $\mathrm{kg} / \mathrm{s}^{2} \Rightarrow k_{c}=708.062 \Rightarrow \lambda_{c} \approx 8.87 \mathrm{~mm}$.

For $U_{1}=21 \mathrm{~m} / \mathrm{s}, U_{2}=0 \mathrm{~m} / \mathrm{s}, \rho_{1}=688 \mathrm{~kg} / \mathrm{m}^{3}, \rho_{2}=1.429 \mathrm{~kg} / \mathrm{m}^{3}, \sigma=0.002014$ $\mathrm{kg} / \mathrm{s}^{2} \Rightarrow k_{c}=312255.605 \Rightarrow \lambda_{c} \approx 20.12 \mu \mathrm{m}$.

For $U_{1}=25 \mathrm{~m} / \mathrm{s}, U_{2}=0 \mathrm{~m} / \mathrm{s}, \rho_{1}=688 \mathrm{~kg} / \mathrm{m}^{3}, \rho_{2}=1.429 \mathrm{~kg} / \mathrm{m}^{3}, \sigma=0.002014$ $\mathrm{kg} / \mathrm{s}^{2} \Rightarrow k_{c}=442539.123 \Rightarrow \lambda_{c} \approx 14.19 \mu \mathrm{m}$.

For $U_{1}=50 \mathrm{~m} / \mathrm{s}, U_{2}=0 \mathrm{~m} / \mathrm{s}, \rho_{1}=688 \mathrm{~kg} / \mathrm{m}^{3}, \rho_{2}=1.429 \mathrm{~kg} / \mathrm{m}^{3}, \sigma=0.002014$ $\mathrm{kg} / \mathrm{s}^{2} \Rightarrow k_{c}=1770156.491 \Rightarrow \lambda_{c} \approx 3.54 \mu \mathrm{m}$.

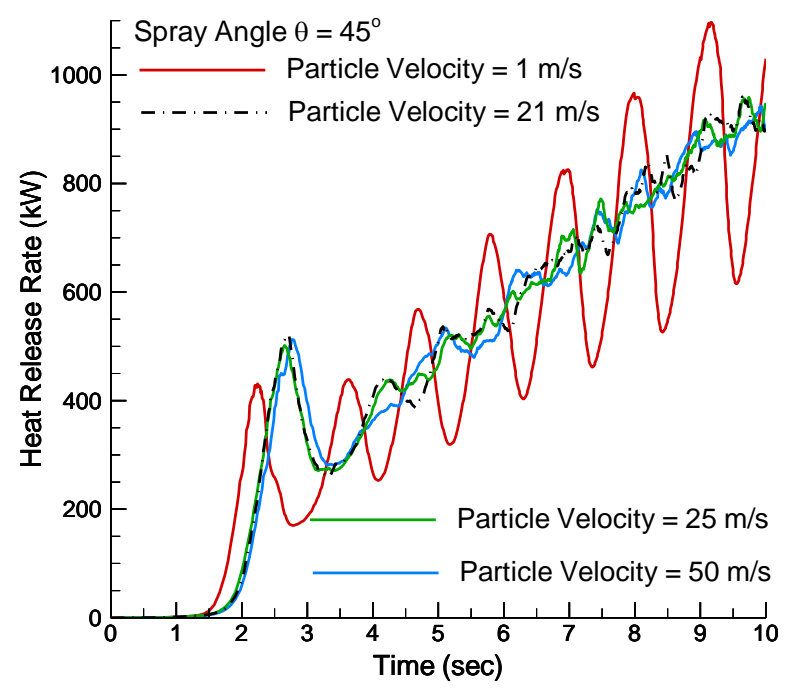

Figure 8. GHRR for varying droplet velocities.

Figure 8 depicts the GHRR values for droplet velocities $1 \mathrm{~m} / \mathrm{s}, 21 \mathrm{~m} / \mathrm{s}, 25$ $\mathrm{m} / \mathrm{s}$ and $50 \mathrm{~m} / \mathrm{s}$. The highest GHRR values for droplet velocities in each case were noted to be $1096.99 \mathrm{~kW}$ at 9.17 seconds; $962.94 \mathrm{~kW}$ at 9.67 seconds; $959.05 \mathrm{~kW}$ at 9.74 seconds; and $942.72 \mathrm{~kW}$ at 9.93 seconds respectively for the simulation time of 10 seconds. At the end of 10 seconds, GHRR values for droplet velocities $1 \mathrm{~m} / \mathrm{s}, 25 \mathrm{~m} / \mathrm{s}$ and $50 \mathrm{~m} / \mathrm{s}$ had $14.36 \%, 6.27 \%$ and $-0.71 \%$ difference respectively from the base value at $21 \mathrm{~m} / \mathrm{s}$. 


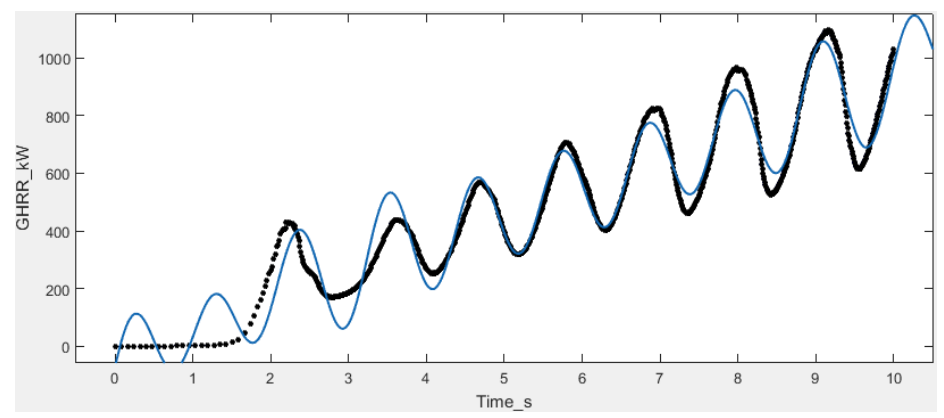

(a)

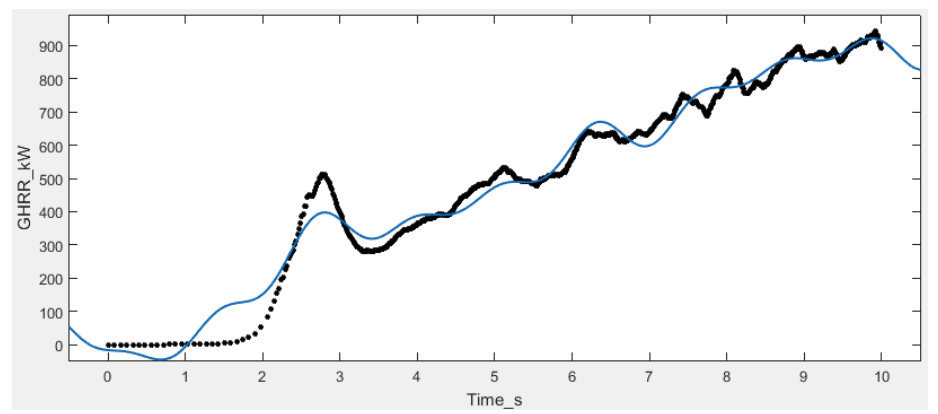

(b)

Figure 9. Curve fitting plot of GHRR for droplet velocities (a) $1 \mathrm{~m} / \mathrm{s}$ (b) $50 \mathrm{~m} / \mathrm{s}$.

Figure 9 depicts two instances of the curve fitting done for the plots obtained for variation in droplet velocity. The best fit was found to be sinusoidal in nature.

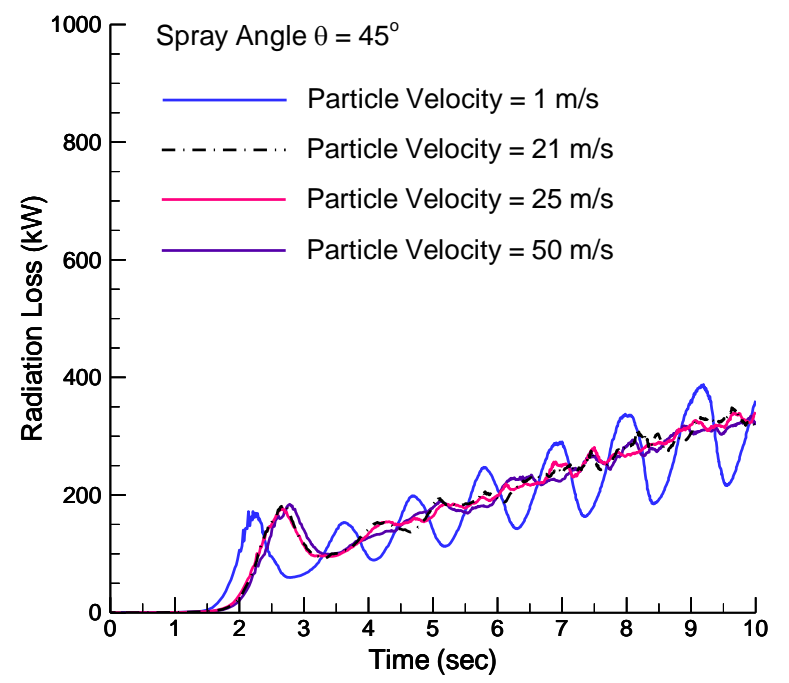

Figure 10. Radiation losses for varying droplet velocities. 


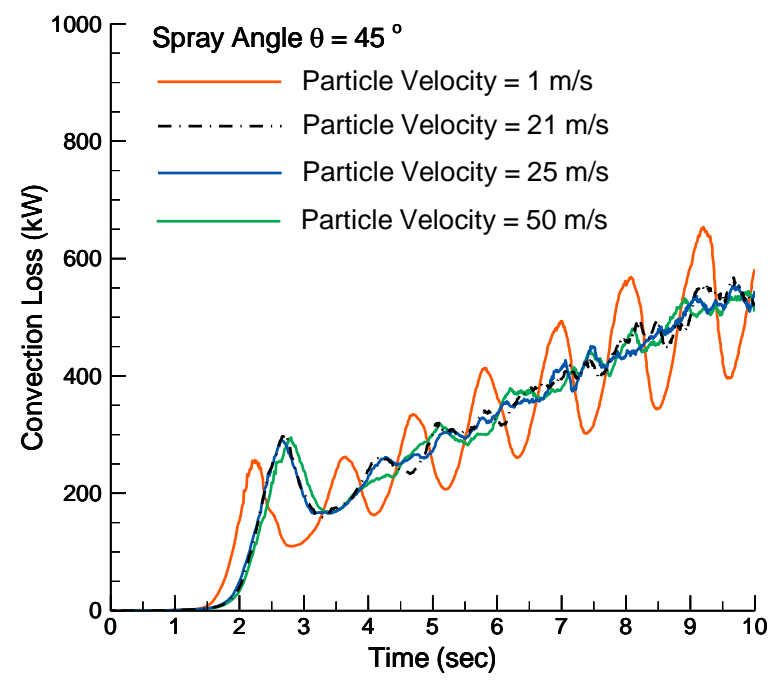

Figure 11. Convection losses for varying droplet velocities.

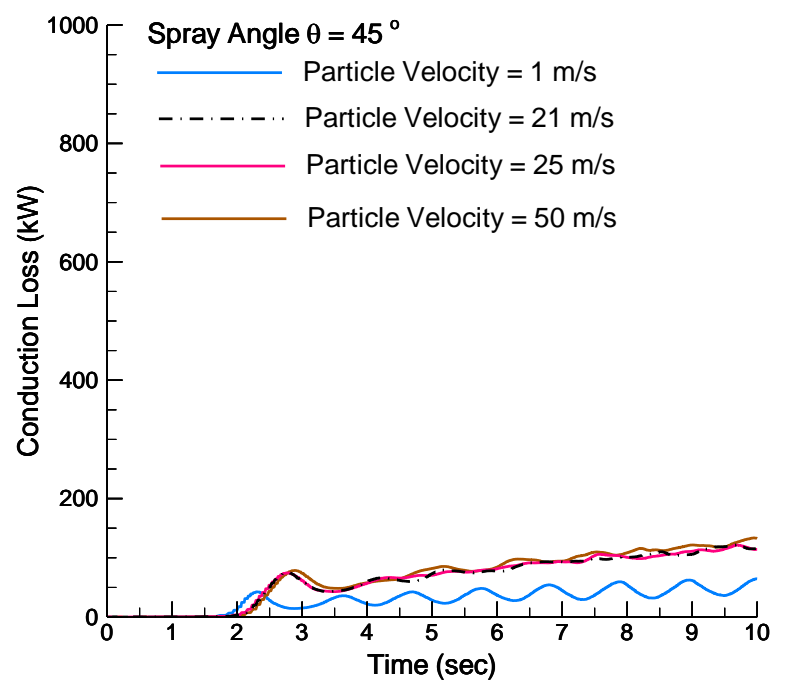

Figure 12. Conduction losses for varying droplet velocities.

Figure 10 depicts the radiation loss values for droplet velocities $1 \mathrm{~m} / \mathrm{s}, 21$ $\mathrm{m} / \mathrm{s}, 25 \mathrm{~m} / \mathrm{s}$ and $50 \mathrm{~m} / \mathrm{s}$. The highest radiation loss values for droplet velocities in each case were noted to be $388.02 \mathrm{~kW}$ at 9.19 seconds; $348.56 \mathrm{~kW}$ at 9.63 seconds; $343.71 \mathrm{~kW}$ at 10 seconds; and $333.98 \mathrm{~kW}$ at 9.92 seconds respectively for the simulation time of 10 seconds. At the end of 10 seconds, radiation loss values for droplet velocities $1 \mathrm{~m} / \mathrm{s}, 25 \mathrm{~m} / \mathrm{s}$ and $50 \mathrm{~m} / \mathrm{s}$ had $12.93 \%, 7.71 \%$ and $0.04 \%$ difference respectively from the base value at $21 \mathrm{~m} / \mathrm{s}$. 
Figure 11 depicts the convection loss values for droplet velocities $1 \mathrm{~m} / \mathrm{s}$, $21 \mathrm{~m} / \mathrm{s}, 25 \mathrm{~m} / \mathrm{s}$ and $50 \mathrm{~m} / \mathrm{s}$. The highest convection loss values for droplet velocities in each case were noted to be $653.73 \mathrm{~kW}$ at 9.20 seconds; $567.57 \mathrm{~kW}$ at 9.67 seconds; $554.27 \mathrm{~kW}$ at 9.75 seconds; and $543.96 \mathrm{~kW}$ at 9.90 seconds respectively for the simulation time of 10 seconds. At the end of 10 seconds, convection loss values for droplet velocities $1 \mathrm{~m} / \mathrm{s}, 25 \mathrm{~m} / \mathrm{s}$ and $50 \mathrm{~m} / \mathrm{s}$ had $11.59 \%, 6.17 \%$ and $-2.32 \%$ difference respectively from the base value at $21 \mathrm{~m} / \mathrm{s}$.

Figure 12 depicts the conduction loss values for droplet velocity $1 \mathrm{~m} / \mathrm{s}, 21$ $\mathrm{m} / \mathrm{s}, 25 \mathrm{~m} / \mathrm{s}$ and $50 \mathrm{~m} / \mathrm{s}$. The highest conduction loss values for droplet velocities in each case were noted to be $64.43 \mathrm{~kW}$ at 9.99 seconds; $121.89 \mathrm{~kW}$ at 9.69 seconds; $121.45 \mathrm{~kW}$ at 9.68 seconds; and $133.65 \mathrm{~kW}$ at 9.94 seconds respectively for the simulation time of 10 seconds. At the end of 10 seconds, conduction loss values for droplet velocities $1 \mathrm{~m} / \mathrm{s}, 25 \mathrm{~m} / \mathrm{s}$ and $50 \mathrm{~m} / \mathrm{s}$ had $-44.11 \%,-0.37 \%$ and $15 \%$ difference respectively from the base value at $21 \mathrm{~m} / \mathrm{s}$.

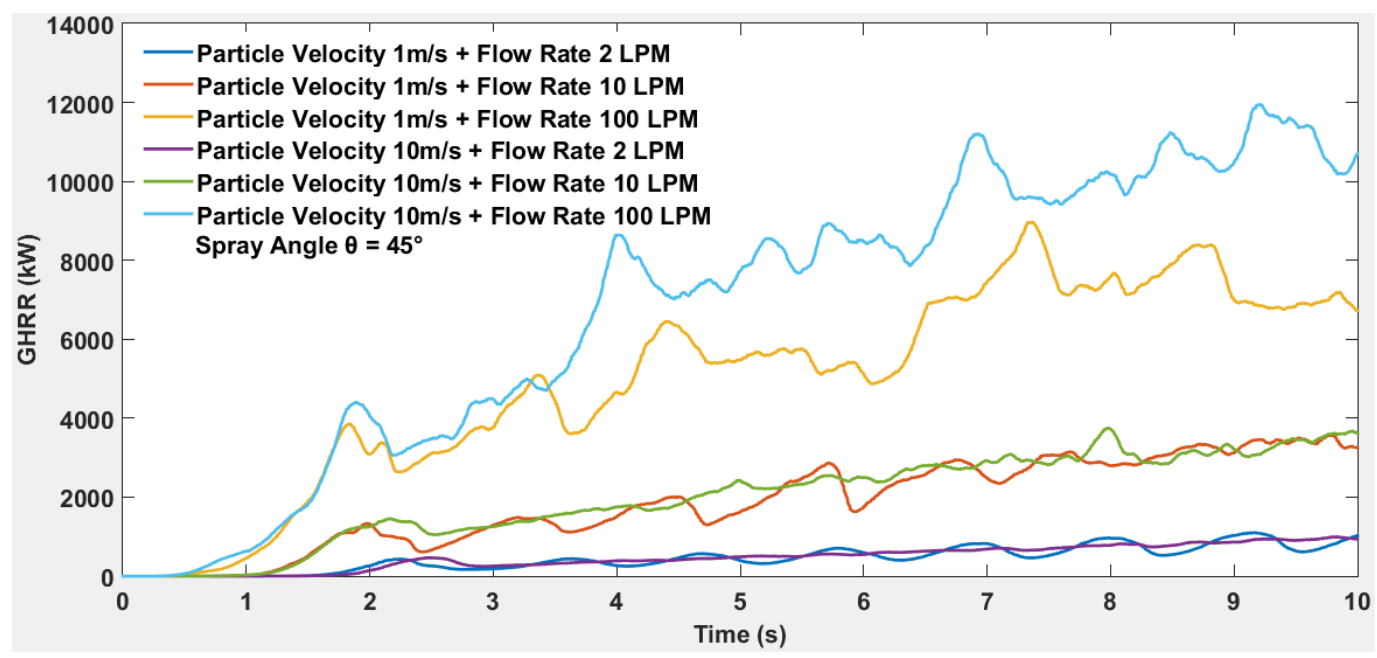

Figure 13. GHRR for droplet velocities $1 \mathrm{~m} / \mathrm{s}$ and $10 \mathrm{~m} / \mathrm{s}$ for flow rates $2 \mathrm{LPM}, 10$ LPM and 100 LPM at spray angle $45^{\circ}$.

From Figure 13, we can see that higher values of droplet velocity relatively decrease the amplitudes of the heat release fluctuations for lower and intermediate flow rates $(\sim 1 \mathrm{~m} / \mathrm{s}$ and $10 \mathrm{~m} / \mathrm{s}$ respectively) but for higher flow rates, variation in droplet velocity doesn't cause substantial variation in amplitudes. From prior studies, it is known that higher the amplitude of flow perturbations, higher is the flame liftoff. Hence, from this study, it is recommended to have a 
minimum droplet velocity of the order of $\sim 10 \mathrm{~m} / \mathrm{s}$ for burners of similar specifications as the one taken in this study.

It can be observed from Figure 14 that the Nusselt number value decreases as droplet velocity increases. This is because higher the droplet velocity more is the interaction of the flame with the steel pan placed underneath the nozzles. This leads to increased conduction loss of the flame. The Nusselt number also reaches a relatively steadier value for higher values of droplet velocity of the order of $\sim 10$ $\mathrm{m} / \mathrm{s}$ and above; for lower volume flow rates of the order of $\sim 1$ LPM because of the limitations on the heat conducting capacity of the steel pan due to its fixed thermal conductivity, specific heat and surface area/volume.

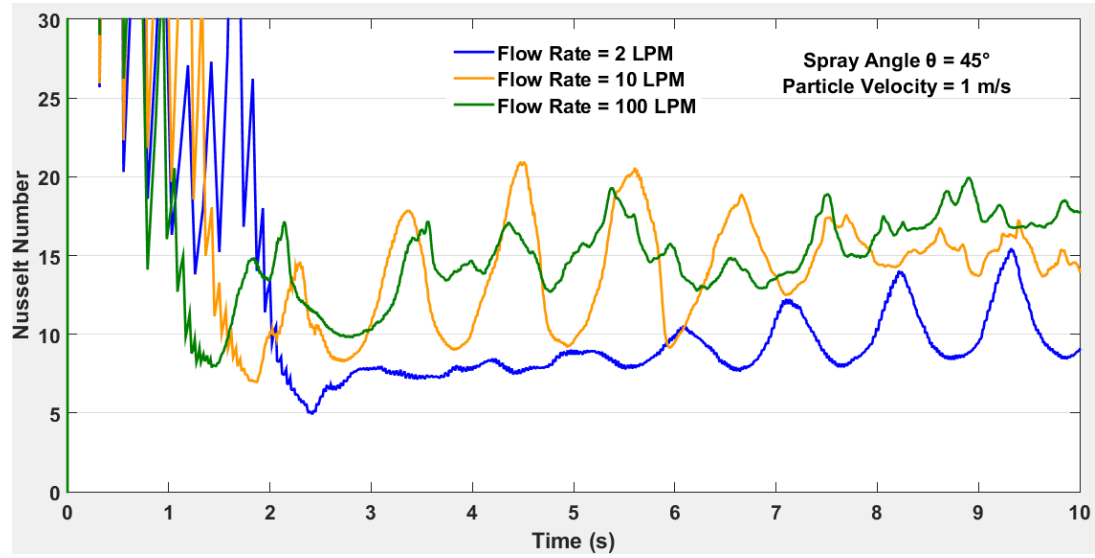

(a)

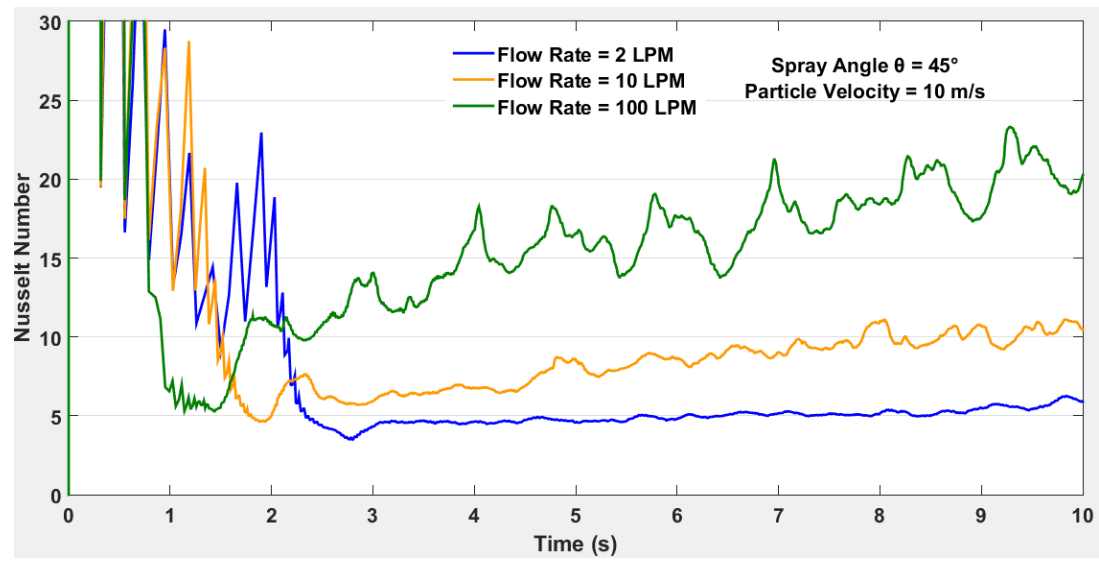

(b) 


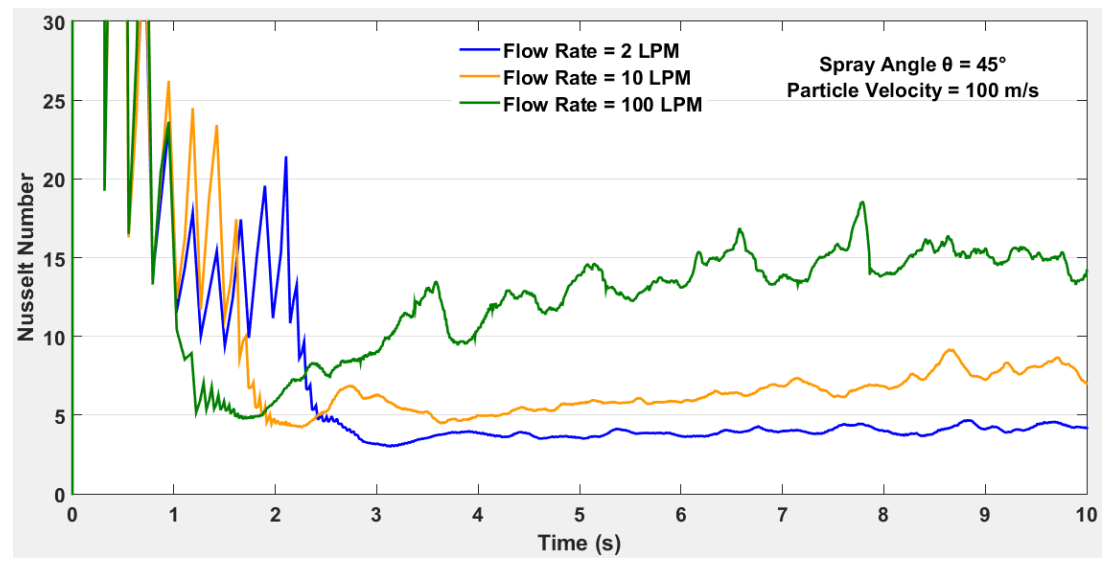

(c)

Figure 14. Nusselt number values for varying flow rates and droplet velocities for spray angle $45^{\circ}$.

Figure 15 shows the GHRR per unit volume $\left(\mathrm{kW} / \mathrm{m}^{3}\right)$ contours for the droplet velocity $1 \mathrm{~m} / \mathrm{s}$, spray angle $45^{\circ}$ and flow rate 2 LPM for variation in time.

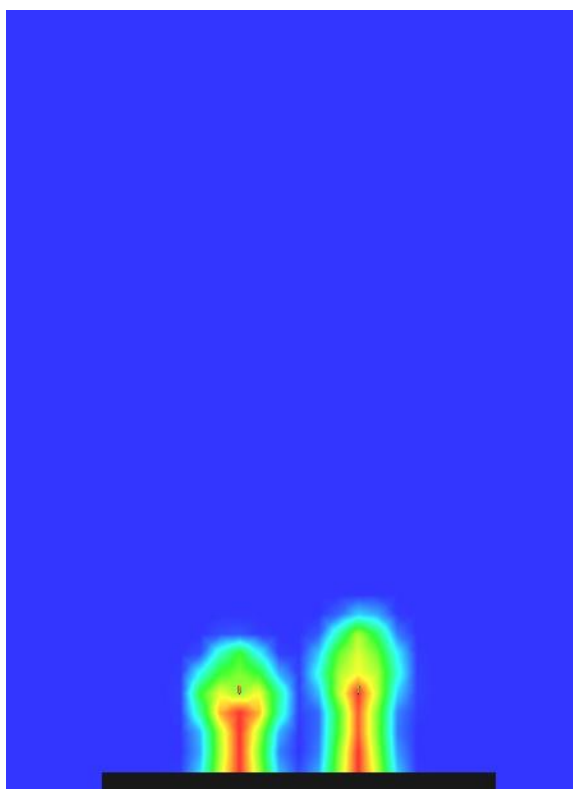

(a)
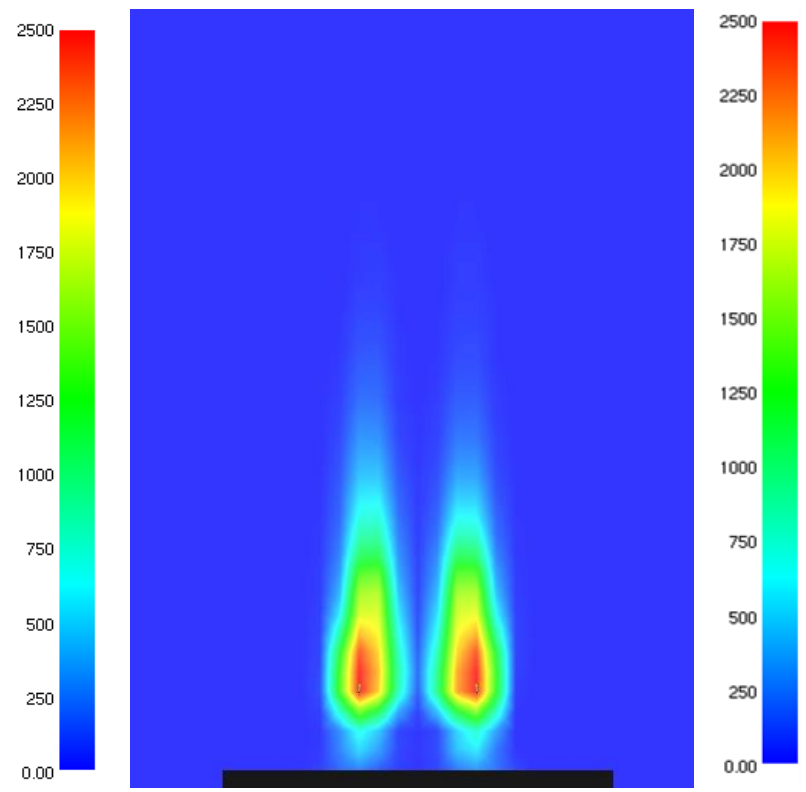

(b) 


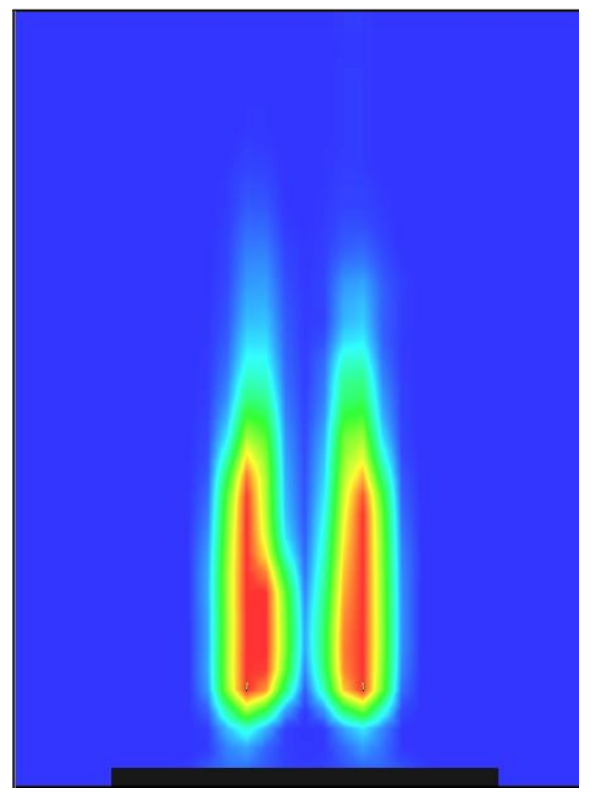

(c)
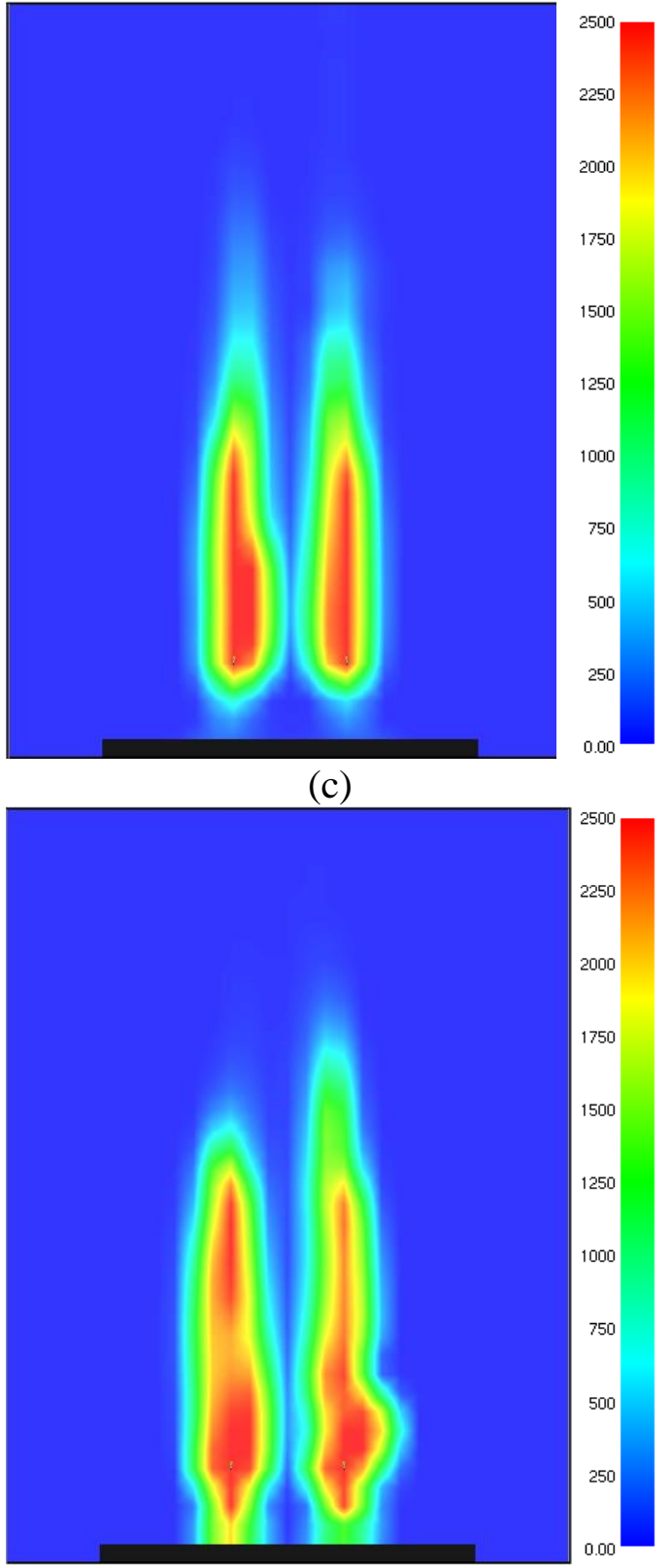
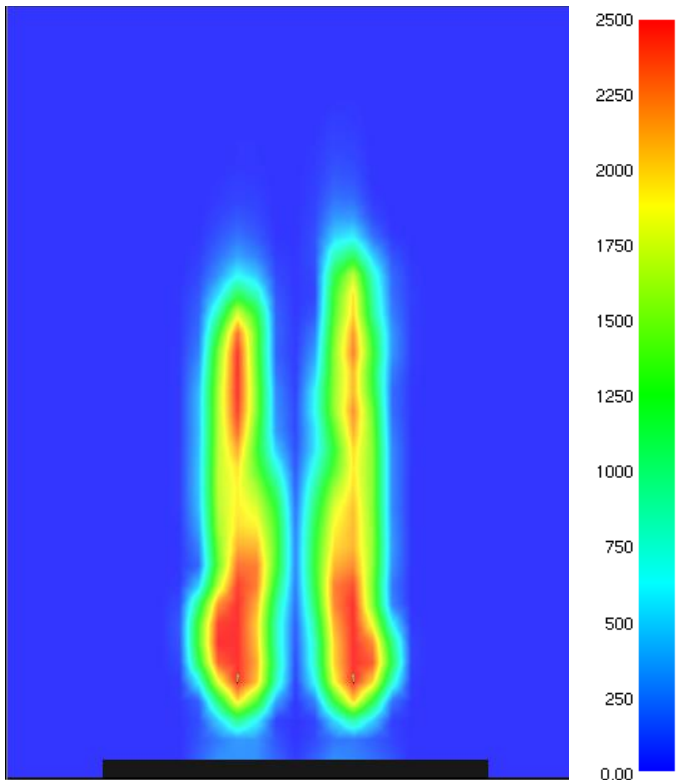

(d)

(e)

Figure 15. Contours of GHRR per unit volume $(\mathrm{kW} / \mathrm{m} 3)$ for droplet velocity 1 $\mathrm{m} / \mathrm{s}$, spray angle $45^{\circ}$ and flow rate 2 LPM at (a) 2 seconds (b) 4 seconds (c) 6 seconds (d) 8 seconds (e) 10 seconds. 


\section{Effect of Volume Flow Rate Variation on Spray Burner Heat Transfer}

Next, the effect of volume flow rate of fuel was seen on spray burner performance. Again, the original base case with the two nozzles facing downwards was taken and keeping the rest of the base parameters untouched, only the flow rates were systematically varied and results were plotted.

Figure 16 depicts the GHRR values for flow rates 0.5 LPM, 2 LPM and 4 LPM. The highest GHRR values for flow rates for each case were noted to be 246 $\mathrm{kW}$ at 9.91 seconds; $962 \mathrm{~kW}$ at 9.99 seconds; and $2024.31 \mathrm{~kW}$ at 9.99 seconds respectively for the simulation time of 10 seconds. At the end of 10 seconds, GHRR values for flow rates 0.5 LPM and 4 LPM had $-75.05 \%$ and $109.56 \%$ difference respectively from the base value at 2 LPM.

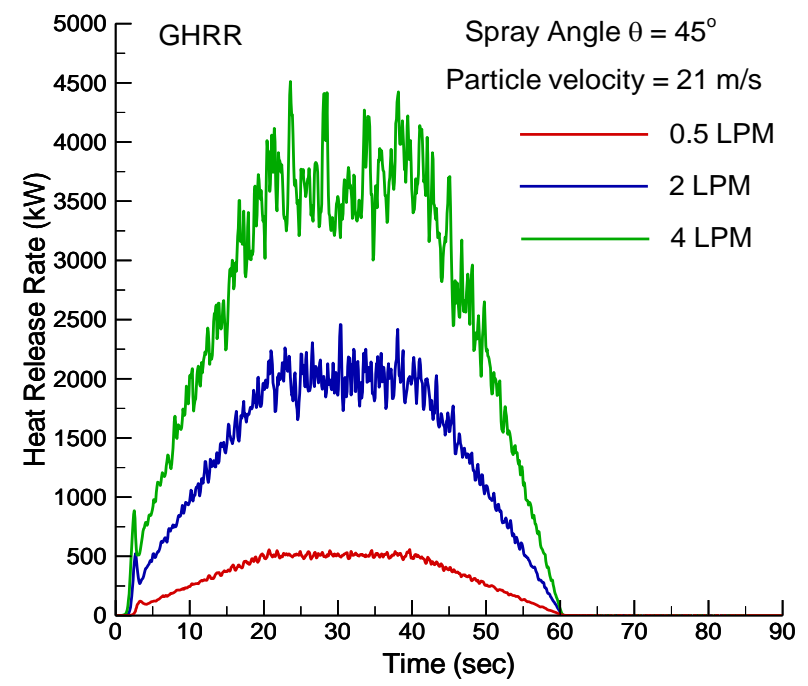

Figure 16. GHRR for varying flow rates.

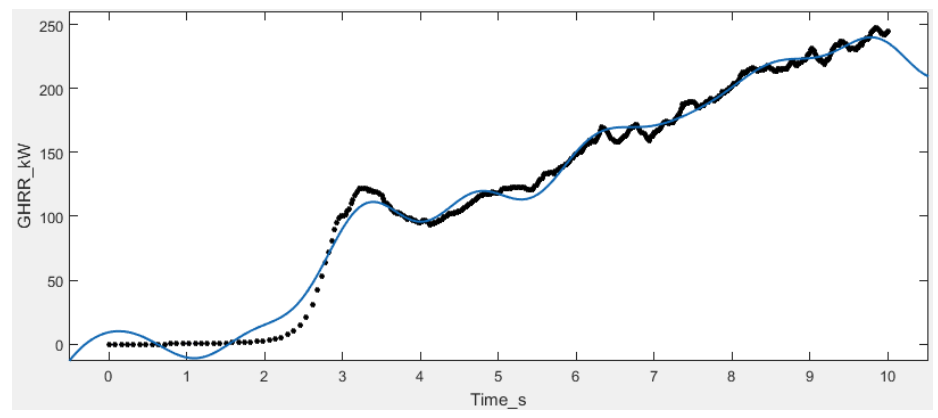

(a) 


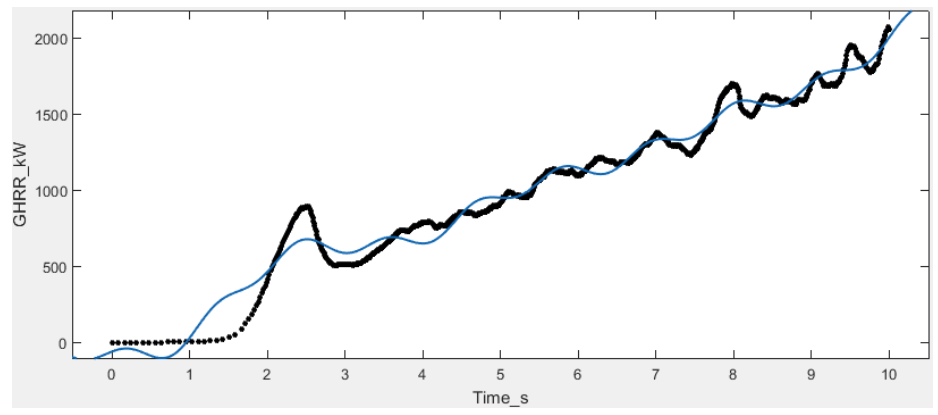

(b)

Figure 17. Curve fitting plot of GHRR for flow rates (a) 0.5 LPM (b) 4 LPM.

Figure 17 depicts two instances of the curve fitting done for the plots obtained for variation in flow rate. The best fit was found to be sinusoidal in nature.

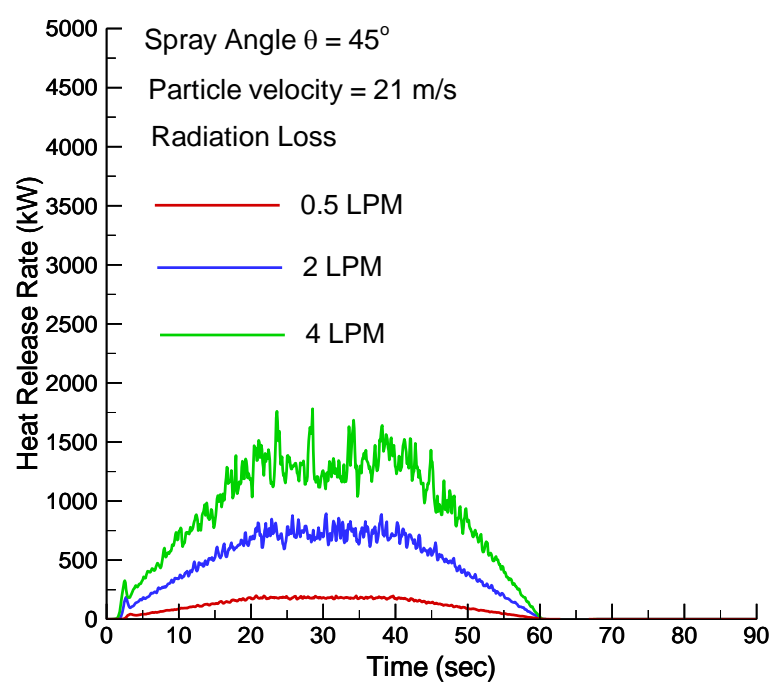

Figure 18. Radiation losses for varying flow rates.

Figure 18 depicts the radiation loss values for flow rates 0.5 LPM, 2 LPM and 4 LPM. The highest radiation loss values for flow rates in each case were noted to be $85.9 \mathrm{~kW}$ at 9.91 seconds; $348 \mathrm{~kW}$ at 9.54 seconds; and $169.23 \mathrm{~kW}$ at 9.54 seconds respectively for the simulation time of 10 seconds. At the end of 10 seconds, radiation loss values for flow rates 0.5 LPM and 4 LPM had $-75.39 \%$ and $116.19 \%$ difference respectively from the base value at 2 LPM. 


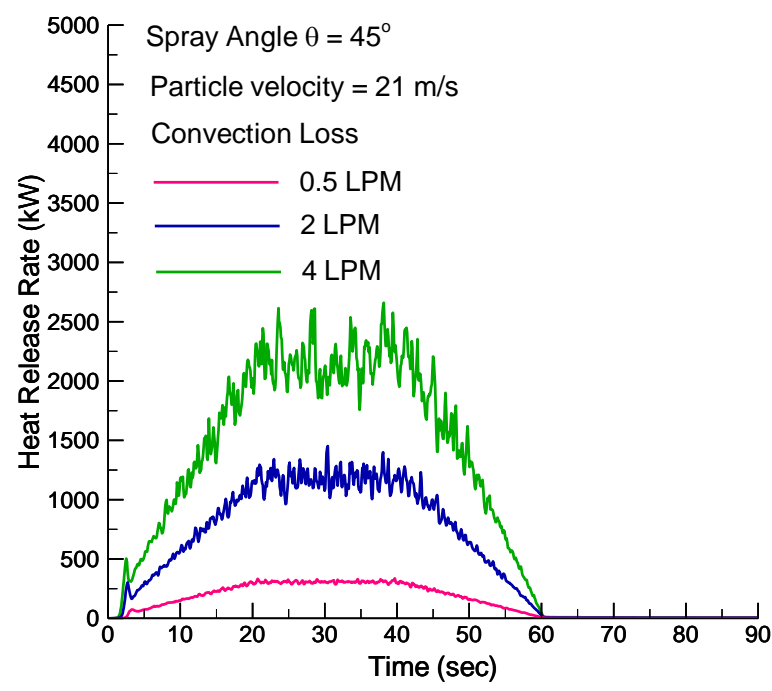

Figure 19. Convection losses for varying flow rates.

Figure 19 depicts the convection loss values for flow rates 0.5 LPM, 2 LPM and 4 LPM. The highest convection loss values for flow rates in each case were noted to be $150 \mathrm{~kW}$ at 9.22 seconds; $565 \mathrm{~kW}$ at 9.99 seconds; and 1174.84 $\mathrm{kW}$ at 9.99 seconds respectively for the simulation time of 10 seconds. At the end of 10 seconds, convection loss values for flow rates 0.5 LPM and 4 LPM had $74.24 \%$ and $106.67 \%$ difference respectively from the base value at 2 LPM.

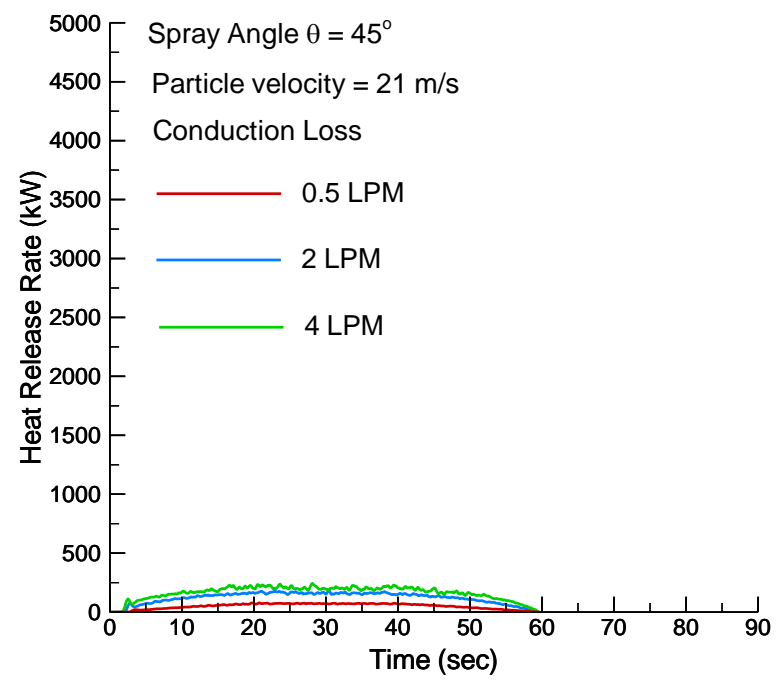

Figure 20. Conduction losses for varying flow rates. 
Figure 20 depicts the conduction loss values for flow rates 0.5 LPM, 2 LPM and 4 LPM. The highest conduction loss values for flow rates in each case were noted to be $40.2 \mathrm{~kW}$ at 10 seconds; $115 \mathrm{~kW}$ at 9.01 seconds; and $115 \mathrm{~kW}$ at 9.99 seconds respectively for the simulation time of 10 seconds. At the end of 10 seconds, conduction loss values for flow rates 0.5 LPM and 4 LPM had $-64.86 \%$ and $50.87 \%$ difference respectively from the base value at 2 LPM.

From Figures 16-20, it is observed that an increase in volume flow rate causes an increase in the generated heat (GHRR) and heat losses in accordance with the fact that larger the quantity of the fuel burnt, larger would be the heat generated and corresponding heat losses. This can also be seen by observing the Nusselt number values in Figure 14 for varying volume flow rates and droplet velocities. The Nusselt number values increase as flow rate increases because the amount of heat generated (and hence, the convective losses) is greater than the amount of heat in contact with (or conducted) by the steel pan placed underneath the spray nozzles. It was also observed that flow rate and droplet velocity have opposing effects on the Nusselt number for given domain specifications, thermal conductivity, emissivity and surface area/volume of the material surroundings.

Higher values of flow rates ( 10 LPM and above) tend to distort the sinusoidal heat release oscillations imparted by flow instabilities.

\section{Effect of Spray Angle Variation on Spray Burner Heat Transfer}

Lastly, the effect of spray angle $(\theta)$ was seen on spray burner performance. Although in reality, the BETE WL $1 / 2$ nozzle only supports 4 standard spray angles $(\theta)$ viz. $15^{\circ}, 30^{\circ}, 45^{\circ}$ and $60^{\circ}$, additional angles of $75^{\circ}$ and $90^{\circ}$ were incorporated in the study to check their effectiveness in spray combustion. Again, the original base case with the two nozzles facing downwards was taken and keeping the rest of the parameters untouched; only the spray angles were systematically varied and results were plotted as in Figures 23-28.

Figure 21 depicts the GHRR values for spray angles $15^{\circ}, 30^{\circ}, 45^{\circ}, 60^{\circ}$, $75^{\circ}$ and $90^{\circ}$. The highest GHRR values for spray angles in each case were noted to be $895 \mathrm{~kW}$ at 9.22 seconds; $969 \mathrm{~kW}$ at 9.82 seconds; $963 \mathrm{~kW}$ at 9.67 seconds; $1000 \mathrm{~kW}$ at 9.71 seconds; $1000 \mathrm{~kW}$ at 9.71 seconds and $904 \mathrm{~kW}$ at 9.65 seconds respectively for the simulation time of 10 seconds. At the end of 10 seconds, 
GHRR for spray angles $15^{\circ}, 30^{\circ}, 60^{\circ}, 75^{\circ}$ and $90^{\circ}$ had $-1.77 \%,-1.76 \%, 9.18 \%$, $8.26 \%$ and $-0.73 \%$ difference respectively from the base value at $45^{\circ}$.

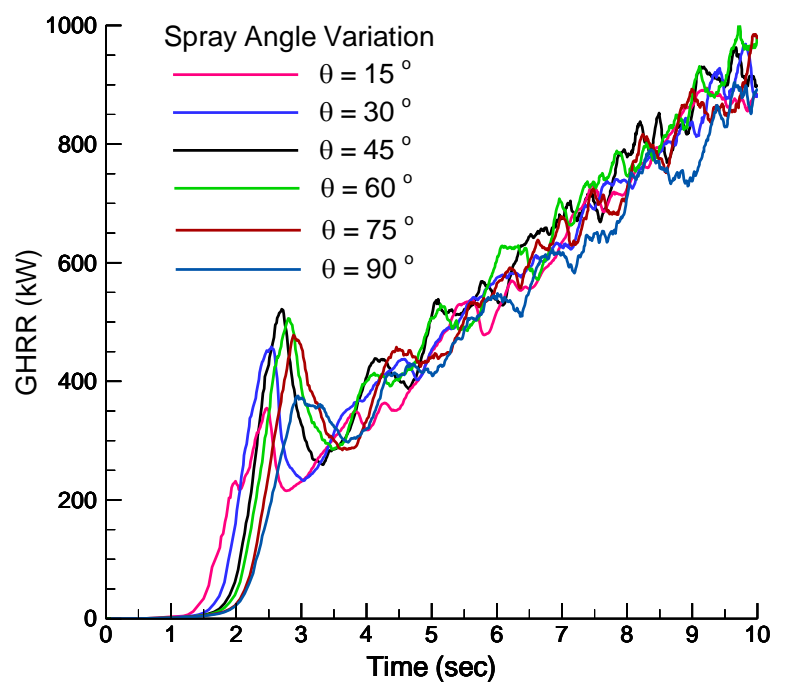

Figure 21. GHRR for varying spray angles.

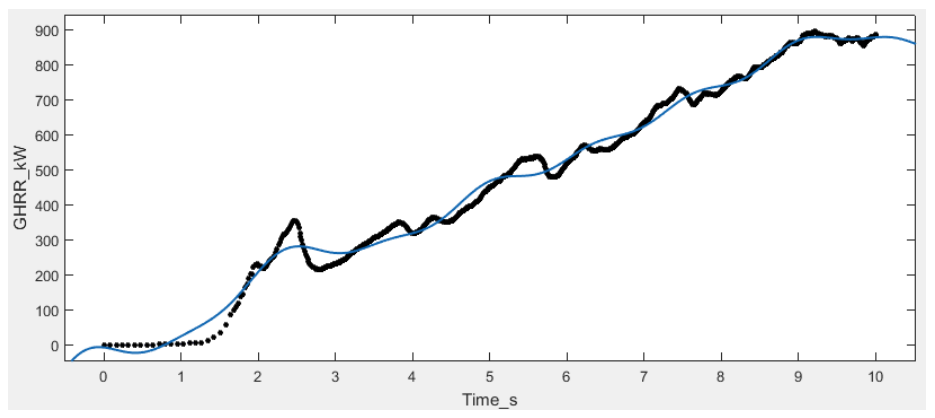

(a)

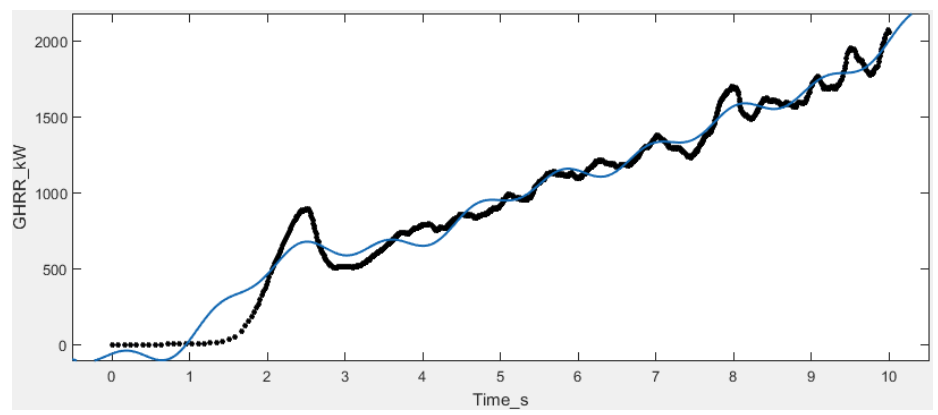

(b)

Figure 22. Curve fitting plot of GHRR for spray angles (a) $15^{\circ}$ (b) $90^{\circ}$. 
Figure 22 depicts two instances of the curve fitting done for the plots obtained for variation in spray angle. The best fit was found to be sinusoidal in nature.

Figure 23 depicts the radiation loss values for spray angles $15^{\circ}, 30^{\circ}, 45^{\circ}$, $60^{\circ}, 75^{\circ}$ and $90^{\circ}$. The highest radiation loss values for spray angles in each case were noted to be $316 \mathrm{~kW}$ at 9.99 seconds; $343 \mathrm{~kW}$ at 9.82 seconds; $349 \mathrm{~kW}$ at 9.63 seconds; $367 \mathrm{~kW}$ at 9.71 seconds; $367 \mathrm{~kW}$ at 9.71 seconds and $326 \mathrm{~kW}$ at 9.82 seconds respectively for the simulation time of 10 seconds. At the end of 10 seconds, radiation losses for spray angles $15^{\circ}, 30^{\circ}, 60^{\circ}, 75^{\circ}$ and $90^{\circ}$ had $-0.87 \%$, $1.36 \%, 10.50 \%, 8.77 \%$ and $-0.60 \%$ difference respectively from the base value at $45^{\circ}$.

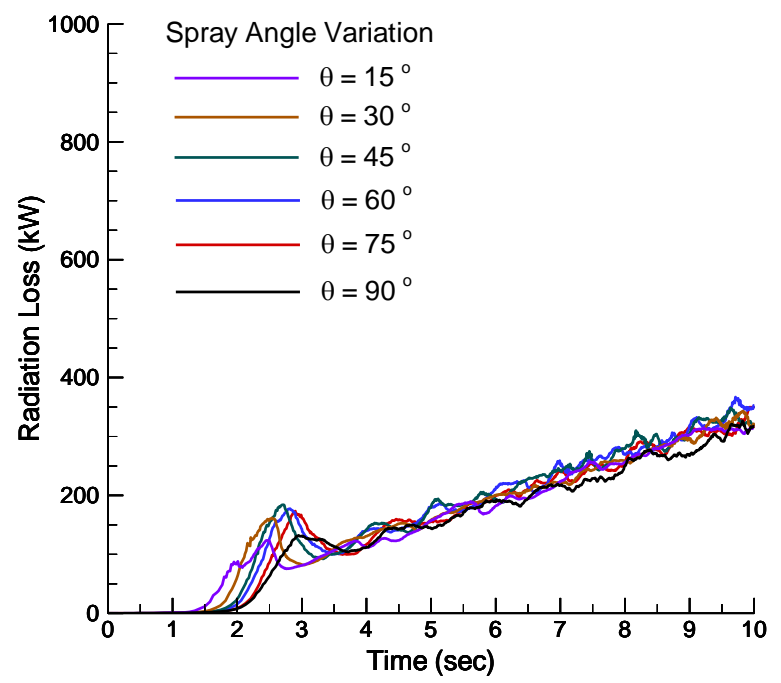

Figure 23. Radiation losses for varying spray angles.

Figure 24 depicts the convection loss values for spray angles $15^{\circ}, 30^{\circ}, 45^{\circ}$, $60^{\circ}, 75^{\circ}$ and $90^{\circ}$. The highest convection loss values for spray angles in each case were noted to be $524 \mathrm{~kW}$ at 9.22 seconds; $568 \mathrm{~kW}$ at 9.80 seconds; $568 \mathrm{~kW}$ at 9.67 seconds; $592 \mathrm{~kW}$ at 9.73 seconds; $592 \mathrm{~kW}$ at 9.73 seconds and $535 \mathrm{~kW}$ at 9.83 seconds respectively for the simulation time of 10 seconds. At the end of 10 seconds, convection losses for spray angles $15^{\circ}, 30^{\circ}, 60^{\circ}, 75^{\circ}$ and $90^{\circ}$ had $1.54 \%,-1.72 \%, 12.10 \%, 9.50 \%$ and $1.82 \%$ difference respectively from the base value at $45^{\circ}$. 


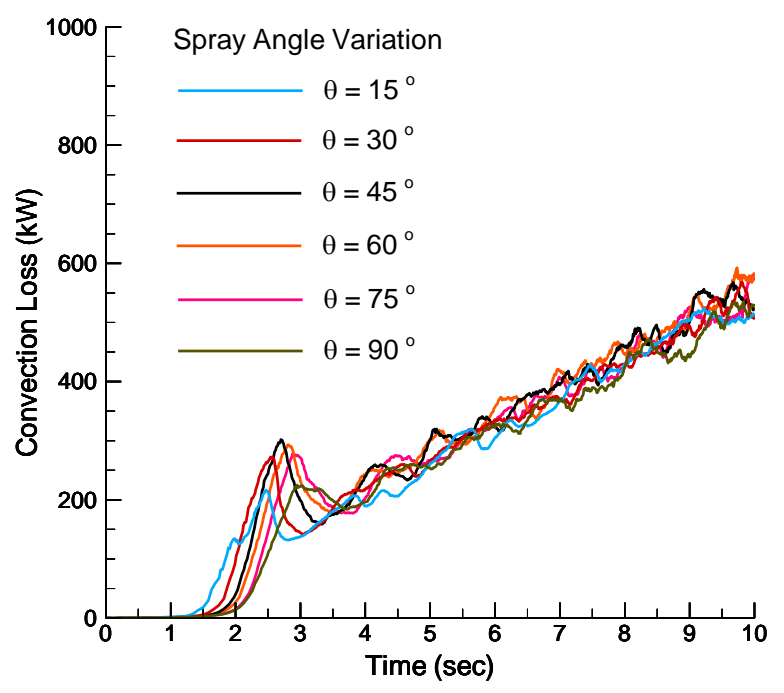

Figure 24. Convection losses for varying spray angles.

Figure 25 depicts the conduction loss values for spray angles $15^{\circ}, 30^{\circ}$, $45^{\circ}, 60^{\circ}, 75^{\circ}$ and $90^{\circ}$. The highest conduction loss values for spray angles in each case were noted to be $89 \mathrm{~kW}$ at 9.31 seconds; $90.4 \mathrm{~kW}$ at 9.85 seconds; $122 \mathrm{~kW}$ at 9.65 seconds; $139 \mathrm{~kW}$ at 10 seconds; $139 \mathrm{~kW}$ at 10 seconds and $135 \mathrm{~kW}$ at 9.70 seconds respectively for the simulation time of 10 seconds. At the end of 10 seconds, conduction losses for spray angles $15^{\circ}, 30^{\circ}, 60^{\circ}, 75^{\circ}$ and $90^{\circ}$ had $25.65 \%,-23.00 \%, 20.33 \%, 22.25 \%$ and $16.04 \%$ difference respectively from the base value at $45^{\circ}$.

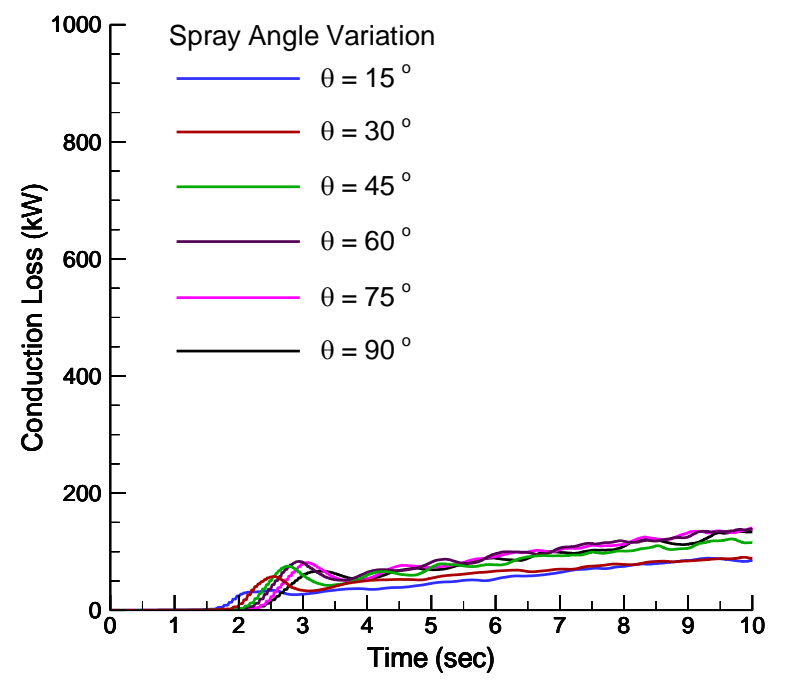

Figure 25. Conduction losses for varying spray angles. 


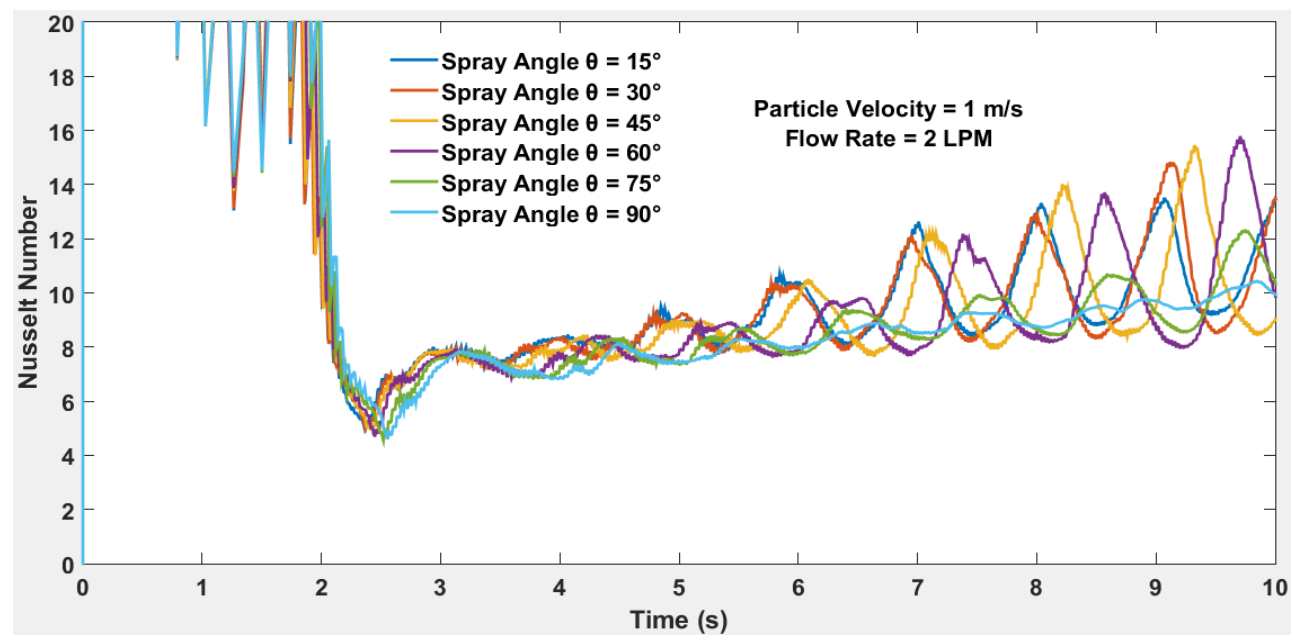

Figure 26. Nusselt number values for varying spray angles, droplet velocity $1 \mathrm{~m} / \mathrm{s}$ and flow rate 2 LPM.

It was observed from a thorough analysis that the perturbation amplitudes of heat release rates increase in magnitude from spray angle $5^{\circ}$ till spray angle $45^{\circ}$ and decrease in magnitude from spray angle $45^{\circ}$ till spray angle $90^{\circ}$ for small droplet velocities $(\sim 1 \mathrm{~m} / \mathrm{s})$ and flow rates $(\sim 1 \mathrm{LPM})$. Thus the $45^{\circ}$ spray angle seemed to impart maximum amplitude to the oscillating heat release rates for small droplet velocities and flow rates. The same can be inferred from Figure 26 depicting the Nusselt number oscillations. On the contrary, variation in spray angle doesn't have a predominant effect on the trend of heat release rates for higher droplet velocities ( $\sim 10 \mathrm{~m} / \mathrm{s}$ and above) and flow rates ( 10 LPM and above) but for practical purposes a spray angle of $45^{\circ}-60^{\circ}$ is generally preferred for optimum spread of fuel, better combustion efficiency, to avoid hot spots (which happen due narrow spray angles tending to produce longer flames) and to avoid an increase in combustor wall temperature.

Figure 27 shows the GHRR per unit volume $(\mathrm{kW} / \mathrm{m} 3)$ contours for the droplet velocity $21 \mathrm{~m} / \mathrm{s}$, spray angle $90^{\circ}$ and flow rate $2 \mathrm{LPM}$ for variation in time. 
Gajjar and M alhotra: Simulations on Optimization of Liquid Spray Burners

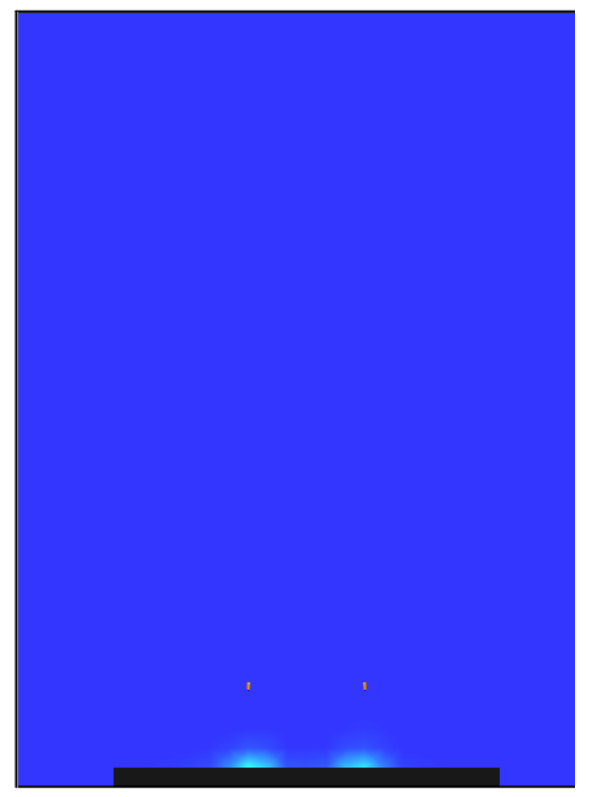

(a)

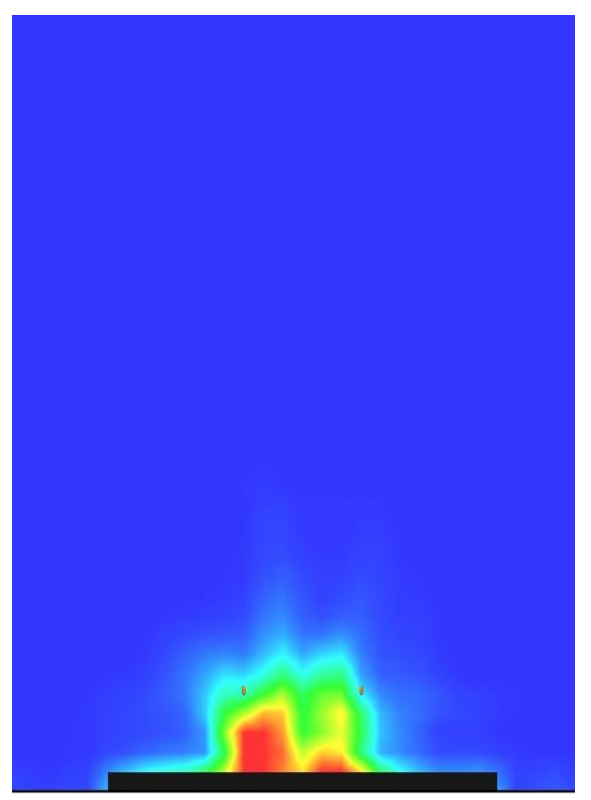

(c)
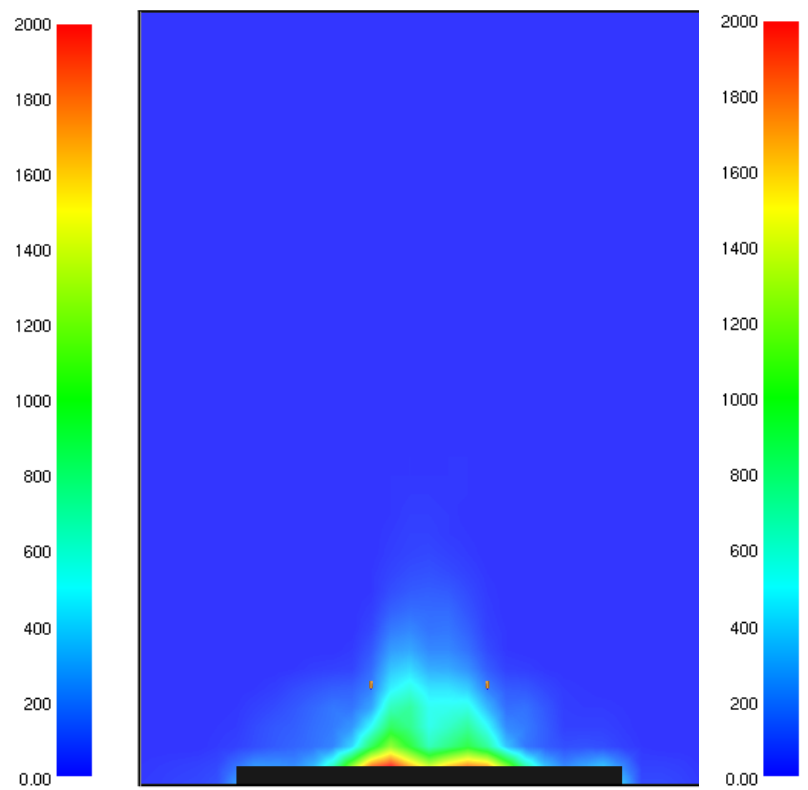

(b)
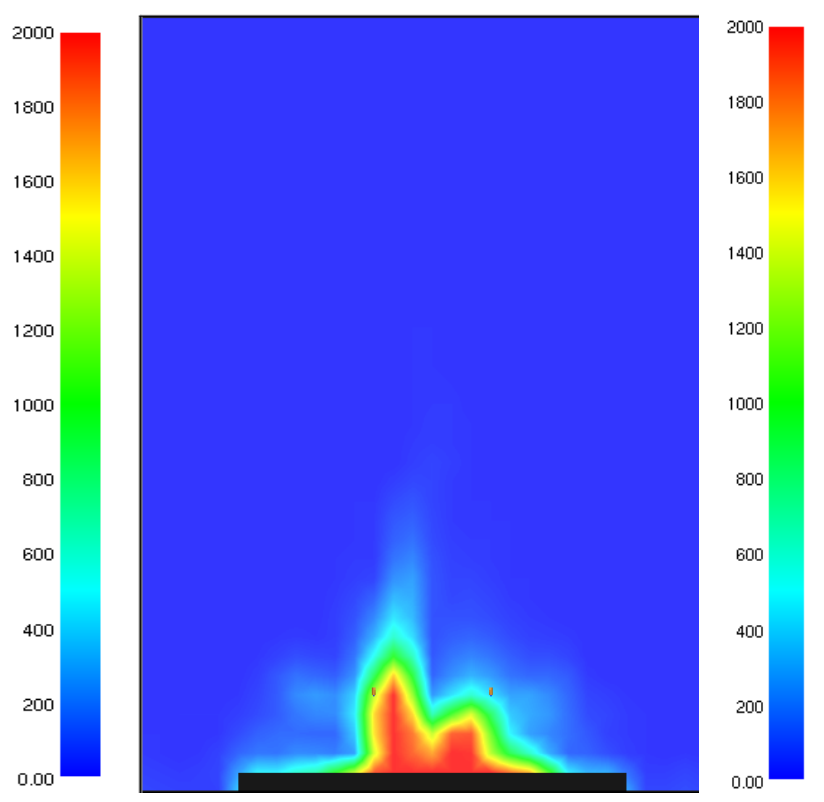

(d) 

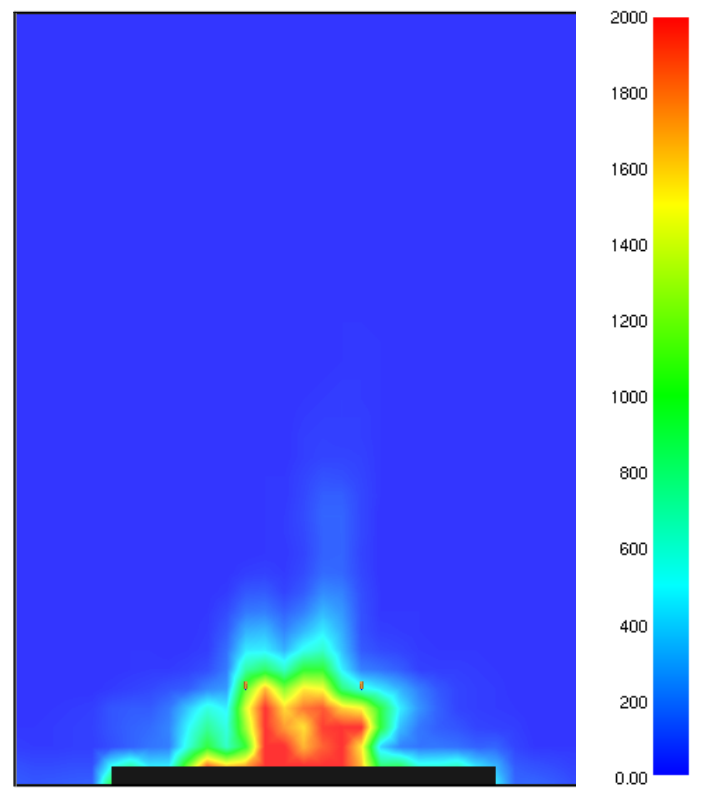

(e)

Figure 27. Contours of GHRR per unit volume $(\mathrm{kW} / \mathrm{m} 3)$ for droplet velocity 21 $\mathrm{m} / \mathrm{s}$, spray angle $90^{\circ}$ and flow rate 2 LPM at (a) 2 seconds (b) 4 seconds (c) 6 seconds (d) 8 seconds (e) 10 seconds.

\section{Ranges of Combustion Instability from the Perspective of Energy Losses}

In this study, an attempt was made to categorize combustion instability from the perspective of energy losses by defining a non-dimensional number ratio named as the "Gajjar-Malhotra Instability Number" which can be obtained by dividing the unoptimized heat release rate by the optimized heat release rate for a given burner and domain specifications. The base case of droplet velocity $21 \mathrm{~m} / \mathrm{s}$, flow rate 2 LPM and spray angle $45^{\circ}$ was taken as the optimized case for the given domain specifications. The heat release rates from all the cases of varying droplet velocity, spray angle and flow rate were respectively divided by the heat release rates of the base case and the ratio values were plotted against time as shown in Figure 30. Combustion instability zones were defined based on the average ratio values as follows:

- Low Scale Instability (LSI): $\quad 0-1$

- Medium Scale Instability (MSI): $1-5$

- High Scale Instability (HSI): $>5$ 
The low scale instability (LSI) corresponds to instabilities which are negligible in magnitude and due to which systems don't undergo damage. This is considered to be the ideal range for systems to operate in. Most system optimizations done in industry aim to bring systems under this particular working range. Medium scale instability (MSI) corresponds to instabilities which can cause system damage but the damage is reversible/recoverable. It is the practical working range for most of the present combustion systems. High scale instability (HSI) corresponds to instabilities which cause grave system damage mainly due to structural failure. Systems falling in this range can't be recovered once the damage is done and shouldn't be used as they tend to be highly unstable in nature. Also, there are tremendous financial losses associated with this instability.

From the study so far, it can be inferred that all controlling parameters viz. droplet velocity, flow rate and spray angle have effects on combustion instability and the order of parameters from maximum to minimum degree of effect is as follows: Flow rate $>$ Droplet velocity $>$ Spray Angle. This can again be verified from Figure 28. The results obtained for spray burners thus far can be very well extended to other applications too.

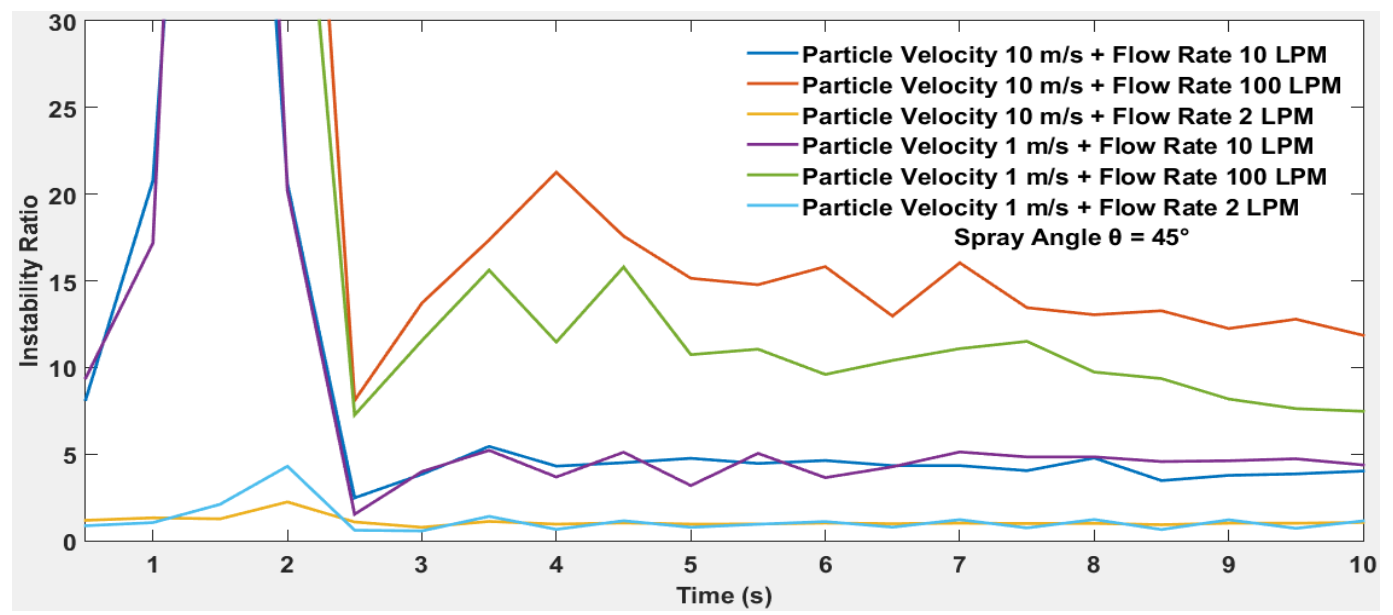

Figure 28. Instability ratios.

\section{Conclusions}

Curve fitting of all the Generated Heat Release Rate (GHRR) and Heat loss plots was done and it was found that all the plots could be roughly defined by a sinusoidal fit represented by the formula, $f(x)=a_{1} * \sin \left(b_{1} * x+c_{1}\right)+a_{2} *$ 
$\sin \left(b_{2} * x+c_{2}\right)+a_{3} * \sin \left(b_{3} * x+c_{3}\right)+a_{4} * \sin \left(b_{4} * x+c_{4}\right)+a_{5} \sin \left(b_{5} *\right.$ $x+c_{5}$ ) where $x$ represents the time (in seconds), $f(x)$ represents the heat release rate (in $\mathrm{kW}$ ) as a function of time and coefficients $a_{1}, a_{2}, a_{3}, a_{4}, a_{5}, b_{1}, b_{2}, b_{3}$, $b_{4}, b_{5}, c_{1}, c_{2}, c_{3}, c_{4}$ and $c_{5}$ are constants. It can be observed through the curve fitting done that the overall trend of the plots obtained from simulations is a roughly distorted form of the sinusoidal wave. The distortion arises due to the fact that there are several phenomena taking place during combustion like differential and preferential diffusion, thermal expansion, buoyancy, etc. which affect the intrinsic and hydrodynamic flow instabilities and in turn the heat release rates. At times the phenomena destructively interfere to attenuate the perturbation waves while other times they constructively interfere with the instabilities to amplify the process or even initiate one. The material surroundings (with their respective thermal conductivities, specific heats, densities, emissivity values, surface areas and volumes) also affect combustion by interacting with the flame. The combustion taking place in a burner is an outcome of the feedback loop of the interaction between the various phenomena with the inherent flow instabilities.

The sudden rise in heat release rate approximately between 1.5 to 3.5 seconds is because the flame interacts with the steel pan underneath by transferring heat to it through conduction. This process of heat transfer reaches an equilibrium state after a period of time and thus the heat release rate value comes back to normal at around 3.5 seconds.

The order of heat release fluctuations has been found to resonate with the order of instabilities present in the flow field. Higher values of droplet velocity relatively decrease the amplitude of the heat release fluctuations for lower and intermediate flow rates ( 1 LPM and 10 LPM respectively) but for higher flow rates, variation in droplet velocity don't cause substantial variation in amplitudes. It is recommended to have a minimum droplet velocity of the order of $\sim 10 \mathrm{~m} / \mathrm{s}$ for burners of similar specifications as the one taken in the study.

Increase in volume flow rate led to an increase in the GHRR and heat losses. Higher values of flow rates ( 10 LPM and above) for a fixed nozzle orifice diameter were seen to distort the sinusoidal heat release oscillations.

Heat release rates tend to be sensitive to spray angle variation at low droplet velocities $(\sim 1 \mathrm{~m} / \mathrm{s})$ and flow rates $(\sim 1$ LPM) as perturbation amplitudes of 
heat release rates were seen to increase in magnitude from spray angle $5^{\circ}$ till spray angle $45^{\circ}$ and decrease in magnitude from spray angle $45^{\circ}$ till spray angle $90^{\circ}$. The $45^{\circ}$ spray angle imparted maximum amplitude to the oscillating heat release rates for low droplet velocities and flow rates. On the contrary, variation in spray angle didn't have a predominant effect on the trend of heat release rates for higher droplet velocities ( $\sim 10 \mathrm{~m} / \mathrm{s}$ and above) and flow rates ( 10 LPM and above).

Droplet velocity and flow rate have opposing effects on the Nusselt number for given domain specifications, thermal conductivity, emissivity and surface area/volume of the material surroundings. In this study, higher the droplet velocity lower is the Nusselt number because higher droplet velocities lead to more interaction of the flame with the steel pan placed underneath the nozzles causing increased conduction loss of the flame. The Nusselt number was observed to reach a relatively steadier value for higher values of droplet velocity of the order of $\sim 10 \mathrm{~m} / \mathrm{s}$ and above, for lower volume flow rates of the order of $\sim 1$ LPM due to the limitations of the heat conducting capacity of the steel pan. On the contrary, the Nusselt number increases as flow rate increases because the amount of heat generated (and hence, the convective losses) is greater than the amount of heat in contact with (or conducted) by the steel pan placed underneath the spray nozzles.

Combustion instability has been redefined from the energy loss perspective and is categorized based on the instability ratios as Low Scale Instability $(0-1)$, Medium Scale Instability $(1-5)$ and High Scale Instability $(>5)$. The order of parameters from maximum to a minimum degree of effect on instabilities was noted to be as follows: Flow rate > Droplet velocity > Spray Angle. 


\section{References}

Bayvel, L. P., \& Orzechowski, Z. (1993). Liquid atomization. Washington, DC: Taylor \& Francis.

Brown, R. S., Dunlap, R., Young, S. W., \& Waugh, R. C. (1981). Vortex shedding as a source of acoustic energy in segmented solid rockets. Journal of Spacecraft and Rockets, 18(4), 312-319. doi:10.2514/3.57822

Clavin, P. (1985). Dynamic behavior of premixed flame fronts in laminar and turbulent flows. Progress in Energy and Combustion Science, 11(1), 1-59. doi:10.1016/0360-1285(85)90012-7

Crocco, L. (1965). Theoretical studies on liquid-propellant rocket instability. Symposium (International) on Combustion, 10(1), 1101-1128. doi:10.1016/s0082-0784(65)80249-1

Culick, F. E. C., \& Yang, V. (1995). Overview of combustion instabilities in liquid-propellant rocket engines. In Liquid rocket engine combustion instability (Vol. 169, pp. 3-37). essay, Progress in Astronautics and Aeronautics.

Datta, A., \& Som, S. K. (1999). Effects of spray characteristics on combustion performance of a liquid fuel spray in a gas turbine combustor. International Journal of Energy Research, 23(3), 217-228. doi:10.1002/(sici)1099-114x(19990310)23:33.0.co;2-u

Fernandes, E., \& Heitor, M. (1996). Unsteady flames and the Rayleigh criterion. In Unsteady combustion (pp. 1-16).

Flandro, G. A. (1986). Vortex driving mechanism in oscillatory rocket flows. Journal of Propulsion and Power, 2(3), 206-214. doi:10.2514/3.22871

Humphrey, J., \& Culick, F. (1987). Linear and nonlinear stability of acoustics with nonuniform entropy in chambers with mean flow. 19th AIAA, Fluid Dynamics, Plasma Dynamics, and Lasers Conference. doi:10.2514/6.1987-1417

Krebs, W., Bethke, S., Lepers, J., Johnson, C., Sattinger, S., \& Flohr, P. (2005). Thermoacoustic design tools and passive means applied by Siemens power generation. In Combustion instabilities in gas turbine engines: Operational experience, fundamental mechanisms, and modeling (pp. 89112). Progress in Astronautics and Aeronautics.

Lefebvre, A. H. (1989). Atomization and sprays. New York: Hemisphere. 
Locklin, D. W., \& Barrett, R. E. (1975). Guidelines for residential oil-burner adjustments: Oil-burner adjustment procedures to minimize air pollution and to achieve efficient use of fuel. Research Triangle Park, NC: U.S. Environmental Protection Agency, Office of Research and Development, Industrial Environmental Research Laboratory.

McGrattan, K., McDermott, R., Hostikka, S., \& Floyd, J. (2010, September 3). Fire Dynamics Simulator (Version 5) User's Guide [PDF]. Baltimore: National Institute of Standards and Technology.

Mcmanus, K., Poinsot, T., \& Candel, S. (1993). A review of active control of combustion instabilities. Progress in Energy and Combustion Science, 19(1), 1-29. doi:10.1016/0360-1285(93)90020-f

Mongia, H., Held, T., Hsiao, G., \& Pandalai, R. (2005). Incorporation of combustion instability issues into design process: GE aero-derivative and aero engines experience. In Combustion instabilities in gas turbine engines: Operational experience, fundamental mechanisms, and modeling (pp. 43-64). Progress in Astronautics and Aeronautics.

Olson, E. O. (n.d.). Fuel nozzles for oil burners: Technical aspects of applications [PDF]. Bamberg: Delavan Fuel Meeting Products Operation. Retrieved February 2, 2019.

Panchagnula, M. (1999). No smoking! Oilheating Journal of Indoor Comfort Marketing, 4, 23-25.

Panchagnula, M. (2014, November 20). Spray theory and applications. Retrieved February 2, 2019, from https://nptel.ac.in/courses/112106154/

Pandalai, R., \& Mongia, H. (1998). Combustion instability characteristics of industrial engine dry low emission combustion systems. 34th AIAA/ASME/SAE/ASEE Joint Propulsion Conference and Exhibit. doi:10.2514/6.1998-3379

Poinsot, T. J., Trouve, A. C., Veynante, D. P., Candel, S. M., \& Esposito, E. J. (1987). Vortex-driven acoustically coupled combustion instabilities. Journal of Fluid Mechanics, 177(-1), 265. doi:10.1017/s0022112087000958

Raghavan, V. (2016). Combustion technology: Essentials of flames and burners. New York, NY: John Wiley and Sons.

Sewell, J., \& Sobieski, P. (2005). Combustion instability monitoring experience at 
Calpine. In Combustion instabilities in gas turbine engines: Operational experience, fundamental mechanisms, and modeling (pp. 62-147).

Progress in Astronautics and Aeronautics.

Sivashinsky, G. I. (1983). Instabilities, pattern formation, and turbulence in flames. Annual Review of Fluid Mechanics, 15(1), 179-199. doi:10.1146/annurev.fl.15.010183.001143

Summerfield, M. (1951). Project SQUID: A theory of unstable combustion in liquid propellant rocket systems. Journal of the American Rocket Society, 21(5), 108-114. doi:10.21236/ada952489

Williams, A. (1990). Spray combustion in geometrically simple systems. Combustion of Liquid Fuel Sprays, 110-126. doi:10.1016/b978-0-40804113-3.50008-7 